\title{
TREATMENT EFFECTS FOR DISCRETE OUTCOMES WHEN RESPONSES TO TREATMENT VARY AMONG OBSERVATIONALLY IDENTICAL PERSONS: AN APPLICATION TO NORWEGIAN VOCATIONAL REHABILITATION PROGRAMS
}

\author{
Arild Aakvik \\ James J. Heckman \\ Edward J. Vytlacil \\ Technical Working Paper 262 \\ http://www.nber.org/papers/T0262 \\ NATIONAL BUREAU OF ECONOMIC RESEARCH \\ 1050 Massachusetts Avenue \\ Cambridge, MA 02138 \\ September 2000
}

\begin{abstract}
The research of the first author was supported by the University of Bergen, the Meltzer Foundation, and the Foundation for Research in Economics and Business Administration. The research of the second and third authors was supported by NSF 97-09-873 and NIH:R01-HD34958-01 and grants from the Mellon, Spencer and Donner Foundations. We thank Victor Aguirregabiria, Xiaohong Chen, Jean-Pierre Florens, Lars Hansen, Robert LaLonde, and Costas Meghir for helpful comments. The views expressed herein are those of the authors and not necessarily those of the National Bureau of Economic Research.

(C) 2000 by Arild Aakvik, James J. Heckman, Edward J. Vytlacil. All rights reserved. Short sections of text, not to exceed two paragraphs, may be quoted without explicit permission provided that full credit, including (C) notice, is given to the source.
\end{abstract}


Treatment Effects for Discrete Outcomes when Responses to Treatment Vary

Among Observationally Identical Persons: An Application to Norwegian

Vocational Rehabilitation Programs

Arild Aakvik, James J. Heckman, and Edward J. Vytlacil

NBER Technical Working Paper No. 262

September 2000

JEL No. C50, H43, J24, J64

\begin{abstract}
This paper formulates an econometric framework for studying the impact of interventions on discrete outcomes when responses to treatment vary among observationally identical persons. Using a latent variable model that can be linked to well-posed economic models, we show how to define and interpret the average treatment effects, the average effect of treatment on the treated, the marginal treatment effect and the distribution of treatment effects for discrete outcomes. To estimate these parameters and the distribution of treatment effects, we formulate and estimate a discrete choice model with unobservables generated by a factor structure model.

We apply our methods to evaluate the effect of Norwegian Vocational Rehabilitation training programs on employment outcomes for women. We find that applicants to these programs who participate in active training have a $4.6 \%$ higher employment rate than nonparticipants. When we control for the observable characteristics of applicants, we find that the average treatment effects falls to $4.1 \%$. When we control for the unobservables characteristics of applicants, the average treatment effect falls to $-1.4 \%$ and effect of treatment on the treated is $-11 \%$. We also find evidence of substantial heterogeneity in response to training.
\end{abstract}

Arild Aakvik

Department of Economics

University of Bergen

Fosswinckelsg 6

N-5007 Bergen

Norway

arild.aakvik@econ.uib.no
James J. Heckman

Department of Economics

University of Chicago

1126 E. $59^{\text {th }}$ Street

Chicago, IL 60637

and NBER

j-heckman@uchicago.edu

Edward J. Vytlacil

Department of Economics

Stanford University

Landau Economics Building, Room 231

579 Serra Mall

Stanford, CA 94305

vytlacil@stanford.edu 


\section{Introduction}

This paper formulates and estimates an econometric model for evaluating social programs when outcomes are discrete and responses to treatment vary among observationally identical persons. The model can be used to generate a variety of mean treatment effects (treatment on the treated, the average treatment effect and the marginal treatment effect) from a common set of parameters as well as distributions of treatment effects defined on various subpopulations. The latent variables that generate our model can be used to capture the essential features of a variety of well-posed economic models, and allow us to bridge the literatures on structural estimation and treatment effects. Estimates produced from our model are economically interpretable and can be used to conduct out-of-sample forecasts and to pool evidence across studies - the usual benefits of a structural econometric approach.

Discrete outcomes arise in analyses of employment, health and migration. Yet a substantial amount of research in the evaluation literature assumes outcomes are continuous or makes special assumptions for analysis of discrete data outcomes. (See, e.g. Card and Sullivan (1988), Gritz (1993), Gay and Borus (1980), Heckman and Robb (1985). Ham and LaLonde (1996) and Ridder (1986).). The methodology we propose and implement in this paper and a companion technical paper (Aakvik, Heckman and Vytlacil, 1999) is sufficiently flexible to accommodate discrete, continuous and mixed discrete - continuous outcome (e.g. Tobit) variables and can be generalized to panel data settings. In this paper, we focus on single period models with discrete outcomes.

We apply our methods to estimate the impact of Norwegian Vocational Rehabilitation Pro- 
grams (VR) on the employment of women. These programs offer income maintenance payments and training programs for individuals whose medical conditions result in reduced productivity in the labor market. The primary goal of these programs is to allow trainees to re-enter the labor force. Roughly $1.5 \%$ of the Norwegian working age population participates in this program at any time and $0.64 \%$ of Norwegian GNP is spent on these programs in any year. ${ }^{1}$ These percentages are even bigger in Sweden. Despite their importance, these programs have not been previously evaluated.

In this paper we address four questions: (1) What are the effects of applicants' observed and unobserved characteristics on the administrative decision to accept applicants into an on-going VR training program? (2) What is the overall effect of training on employment probabilities? (3) Which groups of individuals benefit most from participation in training? (4) How important is it to control for unobservables in understanding the selection and outcome processes?

At first glance, the Norwegian VR training program appears to be successful. Those women who receive training have employment outcomes about $5 \%$ higher than those who do not receive training. However, if administrators systematically select individuals for training with the highest probability of becoming employed even without receiving training, then the stated difference may overstate the effect of training. On the other hand, if administrators systematically select the worst-off individuals for training, then the mean difference may understate the effect of training.

A second contribution of this paper is to the definition and identification of cream-skimming on observables and unobservables as perceived by the observing economist. A variety of definitions of

\footnotetext{
${ }^{1}$ See Heckman, LaLonde and Smith (1999).
} 
cream-skimming exist in the literature. We present several rigorous definitions of the concept and present methods for determining the empirical importance of cream-skimming from both sources. We find substantial evidence for perverse cream-skimming. People selected into the VR program have both observable and unobservable factors that produce the lowest gains in employment compared to what they would experience without treatment.

Adjusting for observed differences (conditioning on observables or matching) reduces the estimated average training effect $(A T E)$ to $4.3 \%$ and the effect of training on the trained $(T T)$ to 2.8\%. Program administrators systematically select individuals with observable characteristics that are associated with high levels of post-program employment, and this difference in observable characteristics explains about thirty percent of the difference in employment rates between trained and untrained individuals. Since the estimated $A T E$ is larger than the estimated TT, there is some indication that program administrators select individuals who benefit less from training than a randomly person in the population.

Controlling for unobserved variables accentuates these results - reducing ATE to $-1.4 \%$ and $T T$ to $-11 \%$. When we control for unobserved characteristics, the average training effect becomes negative. Program administrators tend to select individuals with observed and unobserved characteristics that make them worse off by receipt of training. Training helps some individuals, but program administrators only infrequently select such individuals into training. Using alternative methods to control for selection into training produces a range of estimated treatment effects, but all such estimated treatment effects are lower than the estimated treatment effects that only control for observed characteristics. Furthermore, all methods that allow for 
selection produce estimates of $T T$ that are lower than the corresponding estimates for $A T E$.

This paper is organized in the following way. In Section 2, we present a class of latent variable models that can be used to generate and produce structure on the Neyman (1923), Fisher (1935), Cox (1958) and Rubin (1978) model of potential outcomes, that can be used to estimate structural econometric models and that can be used to analyze discrete, continuous and mixed discretecontinuous outcomes. ${ }^{2}$ In Section 3, we define commonly used treatment effect parameters in terms of the latent variables, using as a unifying device the marginal treatment effect parameter (MTE) introduced in Heckman (1997). We consider both means and distributions of treatment effects. In Section 4 we present a factor structure model and in Section 5 we discuss empirical implementation and estimation of the model. Section 6 presents background on the Norwegian VR training program and discusses the data. In Section 7, we present estimates of the model. The paper concludes with a summary in Section 8.

\section{Latent Variable Model}

For each person $i$, assume two potential outcomes $\left(Y_{0 i}, Y_{1 i}\right)$ corresponding, respectively, to the potential outcomes in the untreated and treated states. Multiple outcome models are analyzed in Aakvik, Heckman and Vytlacil (1999) and in Heckman and Vytlacil (2000c).

Let $D_{i}=1$ denote the receipt of treatment; $D_{i}=0$ denotes nonreceipt. Let $Y_{i}$ be the measured

\footnotetext{
${ }^{2}$ Heckman and Vytlacil (2000c) relate these statistical models to the causal models of economics.
} 
outcome variable so that

$$
Y_{i}=D_{i} Y_{1 i}+\left(1-D_{i}\right) Y_{0 i}
$$

This is the Neyman-Fisher-Cox-Rubin model of potential outcomes. It is also the switching regression model of Quandt (1972) or the Roy model of income distribution (Roy, 1951; Heckman and Honoré, 1990).

The potential outcome equation for the participation state is

$$
Y_{1 i}=\mu_{1}\left(X_{i}, U_{1 i}\right)
$$

and the potential outcome for the non-participation state is

$$
Y_{0 i}=\mu_{0}\left(X_{i}, U_{0 i}\right)
$$

where $X_{i}$ is a vector of observed random variables and $\left(U_{1 i}, U_{0 i}\right)$ are unobserved random variables. It is assumed that $Y_{0 i}$ and $Y_{1 i}$ are defined for everyone and that these outcomes are independent across persons so that there are no interactions among agents. We assume that the program being evaluated is small so that general equilibrium effects and social interactions are negligible. ${ }^{3}$

This paper assumes a latent variable model generates the indicator variable $D$. Specifically, we assume that the assignment or decision rule for the indicator is generated by a latent variable

\footnotetext{
${ }^{3}$ Heckman, Lochner and Taber (1998a, 1998b) demonstrate the dangers of ignoring these interactions for large scale programs. Lewis (1963) discusses this problem in the context of estimating union relative wage effects.
} 
$D_{i}^{*}:$

$$
\begin{aligned}
& D_{i}^{*}=Z_{i} \beta_{D}-U_{D i} \\
& D_{i}=1 \text { if } D_{i}^{*} \geq 0, D_{i}=0 \text { otherwise, }
\end{aligned}
$$

where $Z_{i}$ is a vector of observed (by the econometrician) random variables and $U_{D i}$ is an unobserved (by the econometrician) random variable. $D_{i}^{*}$ is the net utility or gain to the decision-maker from choosing state 1 . The index structure underlies many models in econometrics (see, e.g., Maddala, 1983) and in psychometrics (see, e.g., Junker and Ellis, 1997). ${ }^{4}$ We assume access to an i.i.d. sample, and will henceforth suppress the $i$ subscripts.

In our empirical application, the outcome variable is dichotomous, and we assume that a linear latent index generates the outcome:

$$
\mu_{j}\left(X, U_{j}\right)=\mathbf{1}\left[X \beta_{j} \geq U_{j}\right]
$$

where $j=1$ for the treated state and $j=0$ for the non-treated state, and where $1[\cdot]$ is the indicator function. However our methods apply more generally to the cases where $\left(Y_{0 i}, Y_{1 i}\right)$ are discrete, continuous or mixed discrete - continuous. (See Aakvik, et.al, 1999).

Throughout most of this paper we will maintain the following assumptions:

(i) $Z \beta_{D}$ is a nondegenerate random variable conditional on $X=x$.

(ii) $\left(U_{D}, U_{1}\right)$, and $\left(U_{D}, U_{0}\right)$ are absolutely continuous with respect to Lebesgue measure on $\Re^{2}$.

\footnotetext{
${ }^{4}$ Vytlacil (2000) shows that the nonparametric version of the latent index model considered in this paper is equivalent to the assumptions imposed in the local average treatment effect framework of Imbens and Angrist (1994).
} 
(iii) $\left(U_{D}, U_{1}\right)$ and $\left(U_{D}, U_{0}\right)$ are independent of $(Z, X)$.

(iv) $Y_{1}$ and $Y_{0}$ have finite first moments.

(v) $1>\operatorname{Pr}(D=1 \mid X)>0$.

Assumption (i) requires an exclusion restriction: there exists a variable that determines the treatment decision but does not directly affect the outcome. ${ }^{5}$ Assumption (iv) is required if mean treatment parameters are to be well defined, and is satisfied trivially when $Y_{1}$ and $Y_{0}$ are binary. Assumption (v) is the standard assumption that for each set of $X$ variables, we observe people in both treated and untreated states, at least in large samples.

Let $F_{U_{D}}$ be the distribution of $U_{D}$, with the analogous notation for the distribution of the other random variables. We define the joint distributions for the unobservables using the notation $F_{D, 1}=F_{U_{D}, U_{1}}$ and $F_{D, 0}=F_{U_{D}, U_{0}}$.

\section{Treatment Parameters}

An important advantage of the latent variable model developed in this paper is that it can be used to generate mean treatment parameters and distributions of treatment parameters from a common set of structural parameters. We first start with an analysis of mean treatment parameters.

\footnotetext{
${ }^{5}$ In our empirical work, the outcome variable is binary and the outcome equations are given by a threshold crossing model with a linear index, $\mu_{j}\left(X, U_{j}\right)=\mathbf{1}\left(X \beta_{j} \geq U_{j}\right)$. Given this assumption, assumption (i) can be weakened to require that $Z \beta_{D}$ is a nondegenerate random variable conditional on $X \beta_{1}=x \beta_{1}$ and nondegenerate conditional on $X \beta_{0}=x \beta_{0}$. In fact, under the factor structure asumption discussed in Section 4, no exclusion restriction is required. See Cameron and Heckman (1998), Aakvik, Heckman and Vytlacil (1999) or Chen, Heckman and Vytlacil (1999).
} 


\subsection{Mean Treatment Parameters}

Let $\Delta$ denote the treatment effect for a given observation, where $\Delta=Y_{1}-Y_{0}$. This personspecific treatment effect is a counterfactual. For a given individual, what would be his or her outcome if he or she received the treatment compared to the case where the person had not received the treatment? One can rarely estimate $\Delta$ for any given person. ${ }^{6}$ Instead, it is more common to work with population means or distributions of these variables. In this section, we examine three different mean parameters within this framework: the marginal treatment effect $(M T E)$, the average treatment effect $(A T E)$, and the effect of treatment on the treated $(T T)$. We consider the distributional parameters corresponding to each mean parameter in the next section. Each mean parameter corresponds to an average value of $\Delta$ but defined on different conditioning sets. MTE gives the average effect for persons who are on the margin of indifference between participating or not for a given value of the instrument. $A T E$ is the average effect for an individual chosen at random from the population of training applicants. $T T$ is the average effect for persons who participate. We consider estimation of the distributions of potential outcomes in the next section. We first define the treatment parameters more generally, and then specialize to the case where the outcome variable is generated by a latent index model.

The first parameter we consider is the marginal treatment effect (MTE) parameter introduced

\footnotetext{
${ }^{6}$ Some panel data estimators identify $\Delta$ for each person. See the discussion in Heckman and Smith (1998) and Heckman, LaLonde and Smith (1999).
} 
in Heckman (1997). ${ }^{7}$ Following Heckman (1997), we define the MTE parameter as

$$
\Delta^{M T E}(x, u)=E\left(\Delta \mid X=x, U_{D}=u\right) .
$$

$\Delta^{M T E}(x, u)$ is the average effect of participating in the program for people who are on the margin of indifference between participation in the program $(D=1)$ or not $(D=0)$ if the instrument is externally set so that $Z \beta_{D}=u$. For values of $u$ close to zero, $\Delta^{M T E}(x, u)$ is the average effect for individuals with unobserved characteristics that make them the most inclined to participate in the program $(D=1)$, and for values of $u$ close to one it is the average treatment effect for individuals with unobserved (by the econometrician) characteristics that make them the least inclined to participate.

The second parameter that we consider in this section is the average effect of treatment on a person selected randomly from the population of individuals with a given value of $X$. The average treatment effect is given by

$$
\Delta^{A T E}(x) \equiv E(\Delta \mid X=x) .
$$

This is related to the marginal treatment effect via the following equation:

$$
\Delta^{A T E}(x)=\int E\left(\Delta \mid X=x, U_{d}=u\right) d F(u)
$$

\footnotetext{
${ }^{7}$ See also Heckman and Smith (1998) and Heckman and Vytlacil (1999, 2000a, 2000b). A version of this parameter was introduced in a generalized Roy model by Björklund and Moffitt (1987). It can also be viewed as the limit form of the LATE parameter of Imbens and Angrist (1994) and Angrist, Graddy and Imbens (1995).
} 
where integration is made over the full support of $U_{D}$. ATE is an average of the MTE parameters. An average treatment effect integrated over the distribution of $X$ is sometimes desired to summarize data. ${ }^{8}$ Thus the following parameter is sometimes sought:

$$
E\left(\Delta^{A T E}\right)=\int \Delta^{A T E}(x) d F_{X}(x)
$$

Averages over subsets of the support of $X$ are also sometimes of interest. The marginal effect of changes in $X$ on the average treatment effect integrating over the distribution of $X$ is sometimes of interest. Let $x_{k}$ denote the $k$ th element of $X$, and assume that $E\left(\mu_{j}\left(X, U_{j}\right) \mid X=x\right)$ is differentiable in $x_{k}$ a.e. $F_{X}$ for $j=0,1$, then a parameter of interest is

$$
E_{X}\left(\frac{\partial E(\Delta \mid X=x)}{\partial x_{k}}\right)=\int \frac{\partial \Delta^{A T E}(x)}{\partial x_{k}} d F_{X}(x)
$$

The mean effect of treatment on the treated is the most commonly estimated parameter (see Heckman and Robb, 1985), and we define it as:

$$
\begin{aligned}
\Delta^{T T}(x, D=1) & \equiv E(\Delta \mid X=x, D=1) \\
& =E\left(\Delta \mid X=x, U_{D} \leq Z \beta_{D}\right) .
\end{aligned}
$$

This parameter is the effect of treatment on an individual drawn at random from the population of individuals who entered the program and have the given value of $X$. The average marginal effect of

\footnotetext{
${ }^{8}$ See, e.g., Heckman, Ichimura, Smith and Todd, 1998.
} 
changes in $X$ on the effect of treatment on the treated is sometimes of interest and can be obtained by integrating over the distribution of $X$ for participants: $E_{X}\left(\frac{\partial E(\Delta \mid D=1, X=x)}{\partial x_{k}} \mid D=1\right)$ $=\int \frac{\partial \Delta^{T T}(x, D=1)}{\partial x_{k}} d F_{X \mid D}(x \mid 1)$.

It will be useful to define a conditional on $Z$ version of $\Delta^{T T}(x, D=1)$ :

$$
\begin{aligned}
\Delta^{T T}(x, z, D=1) & \equiv E(\Delta \mid X=x, Z=z, D=1) \\
& =E\left(\Delta \mid X=x, U_{D} \leq z \beta_{D}\right) \\
& =\frac{1}{\operatorname{Pr}[D=1 \mid Z=z]} \int_{-\infty}^{z \beta_{D}} E\left(\Delta \mid X=x, U_{D}=u\right) d F_{U}(u) .
\end{aligned}
$$

The two versions of $T T$ are related by the following expression:

$$
\Delta^{T T}(x, D=1)=E(\Delta \mid X=x, D=1)=\int \Delta^{T T}(x, z, D=1) d F_{Z \mid X, D}(z \mid x, 1) .
$$

Using Bayes' rule and that fact that $\operatorname{Pr}(D=1 \mid X=x, Z=z)=\operatorname{Pr}(D=1 \mid Z=z)$, we obtain

$$
d F_{Z \mid X, D}(z \mid x, 1)=\frac{\operatorname{Pr}(D=1 \mid Z=z)}{\operatorname{Pr}(D=1 \mid X=x)} d F_{Z \mid X}(z \mid x),
$$

so that we can obtain an expression in terms of $M T E$ as follows:

$$
\begin{aligned}
\Delta^{T T}(x, D & =1) \\
& \left.=\frac{1}{\operatorname{Pr}(D=1 \mid X=x)} \int\left[\int_{-\infty}^{z \beta_{D}} E\left(\Delta \mid X=x, U_{D}=u\right) d F_{U}(u)\right] d F_{Z \mid X}(z \mid x)\right]
\end{aligned}
$$




$$
\begin{aligned}
& \left.=\frac{1}{\operatorname{Pr}(D=1 \mid X=x)} \int\left[\int E\left(\Delta \mid X=x, U_{D}=u\right) 1\left(u \leq z \beta_{D}\right) d F_{Z \mid X}(z \mid x)\right] d F_{U}(u)\right] \\
& =\int E\left(\Delta \mid X=x, U_{D}=u\right) \frac{\operatorname{Pr}(D=1 \mid X=x, U=u)}{\operatorname{Pr}(D=1 \mid X=x)} d F_{U}(u) .
\end{aligned}
$$

Since $\frac{\operatorname{Pr}(D=1 \mid X=x, U=u)}{\operatorname{Pr}(D=1 \mid X=x)}$ is a nonincreasing function of $u$, the $T T$ parameter can be interpreted as a weighted average of marginal treatment effects where individuals who have unobserved characteristics that make them the most inclined to participate in the program (have low $U_{D}$ values) receive the most weight in the average.

Heckman (1997), Heckman and Smith (1998) and Heckman, LaLonde and Smith (1999) discuss the economic questions these three parameters answer. In brief, $M T E$ identifies the effect of an intervention on those induced to change treatment states by the intervention. TT estimates the effect of the program on the entire group of people who participate in it. ATE estimates the effect of the program on randomly selected persons. See Heckman and Vytlacil (2000) for a discussion of the relationships among these parameters.

Consider the special case where the outcome variable is dichotomous and is generated by an underlying linear latent index, $\mu_{j}\left(X, U_{j}\right)=\mathbf{1}\left(X \beta_{j} \geq U_{j}\right)$. In this special case, the mean treatment parameters have the following form:

$$
\begin{aligned}
\Delta^{M T E}(x, u) & =\operatorname{Pr}\left(Y_{1}=1 \mid X=x, U_{D}=u\right)-\operatorname{Pr}\left(Y_{0}=1 \mid X=x, U_{D}=u\right) \\
& =F_{1 \mid D}\left(x \beta_{1} \mid u\right)-F_{0 \mid D}\left(x \beta_{0} \mid u\right) \\
\Delta^{A T E}(x) & =\operatorname{Pr}\left(Y_{1}=1 \mid X=x\right)-\operatorname{Pr}\left(Y_{0}=1 \mid X=x\right) \\
& =F_{U_{1}}\left(x \beta_{1}\right)-F_{U_{0}}\left(x \beta_{0}\right)
\end{aligned}
$$




$$
\begin{aligned}
\Delta^{T T}(x, z, D=1) & =\operatorname{Pr}\left(Y_{1}=1 \mid X=x, Z=z, D=1\right)-\operatorname{Pr}\left(Y_{0}=1 \mid X=x, Z=z, D=1\right) \\
& =\frac{1}{F_{U_{D}}\left(z \beta_{D}\right)}\left[F_{D, 1}\left(z \beta_{D}, x \beta_{1}\right)-F_{D, 0}\left(z \beta_{D}, x \beta_{0}\right)\right] \\
\Delta^{T T}(x, D=1) & =\operatorname{Pr}\left(Y_{1}=1 \mid X=x, D=1\right)-\operatorname{Pr}\left(Y_{0}=1 \mid X=x, D=1\right) \\
& =\frac{1}{E\left(F_{U_{D}}\left(Z \beta_{D}\right) \mid X=x\right)} E_{Z}\left[F_{D, 1}\left(Z \beta_{D}, X \beta_{1}\right)-F_{D, 0}\left(Z \beta_{D}, X \beta_{0}\right) \mid X=x\right],
\end{aligned}
$$

where $F_{j \mid D}\left(t_{j} \mid t_{D}\right)=\operatorname{Pr}\left(U_{j} \leq t_{j} \mid U_{D}=t_{D}\right)$ for $j=0,1$. We now use the latent variable model to define distributional treatment parameters.

\subsection{Distributional Treatment Parameters}

For many questions, knowledge of distributional parameters is required. ${ }^{9}$ Does anybody benefit from the program? Among those treated, what fraction is helped by the program and what fraction is hurt by it? We now consider treatment parameters for the distribution of treatment effects. We first define the distributional treatment parameters more generally, and then specialize to the case where the outcome variables are dichotomous and are generated by a latent index model. For any measurable set $\mathcal{A}$, let $\mathbf{1}_{\mathcal{A}}(\zeta)$ be an indicator variable for the event $\zeta \in \mathcal{A}$. The parameters in section 3.1 are defined as averages of $\Delta$, and we can define the parallel parameters as averages of $\mathbf{1}_{\mathcal{A}}(\Delta)$ by simply substituting $\mathbf{1}_{\mathcal{A}}(\Delta)$ for $\Delta$. Let $\mathcal{A}(x)=\left\{\left(u_{0}, u_{1}\right): \mu_{1}\left(x, u_{1}\right)-\right.$ $\left.\mu_{0}\left(x, u_{0}\right) \in \mathcal{A}\right\}$. Let $F_{0,1}=F_{U_{0}, U_{1}}$.

\footnotetext{
${ }^{9}$ Heckman (1992), Heckman and Smith with Clements, (1997) and Heckman and Smith (1998) emphasize that many criteria for the evaluation of social programs require information on the distribution of treatment effects.
} 
The distributional parameter corresponding to the $M T E$ parameter for the event $\Delta \in \mathcal{A}$ is

$$
\begin{aligned}
E\left[\mathbf{1}_{\mathcal{A}}(\Delta) \mid X=x, U_{D}=u, D=1\right] & =\int \mathbf{1}_{\mathcal{A}}\left(\mu_{1}\left(x, u_{1}\right)-\mu_{0}\left(x, u_{0}\right)\right) d F_{0,1 \mid D}\left(u_{0}, u_{1} \mid u\right) \\
& =\int_{\mathcal{A}(x)} d F_{0,1 \mid D}\left(u_{0}, u_{1} \mid u\right) .
\end{aligned}
$$

A distributional parameter corresponding to the $A T E$ parameter for the event $\Delta \in \mathcal{A}$ is

$$
\begin{aligned}
E\left[\mathbf{1}_{\mathcal{A}}(\Delta) \mid X=x\right] & =\int \mathbf{1}_{\mathcal{A}}\left(\mu_{1}\left(x, u_{1}\right)-\mu_{0}\left(x, u_{0}\right)\right) d F_{0,1}\left(u_{0}, u_{1}\right) \\
& =\int_{\mathcal{A}(x)} d F_{0,1}\left(u_{0}, u_{1}\right) .
\end{aligned}
$$

Likewise, we can define a distributional parameter corresponding to the $T T$ parameter conditional on $Z$ for the event $\Delta \in \mathcal{A}$,

$$
\begin{aligned}
E\left[\mathbf{1}_{\mathcal{A}}(\Delta)\right. & \mid X=x, Z=z, D=1] \\
= & \frac{1}{\operatorname{Pr}(D=1 \mid Z=z)} \int \mathbf{1}_{\left(-\infty, z \beta_{D}\right]}\left(u_{D}\right) \mathbf{1}_{\mathcal{A}}\left(\mu_{1}\left(x, u_{1}\right)-\mu_{0}\left(x, u_{0}\right)\right) d F_{D, 0,1}\left(u_{D}, u_{0}, u_{1}\right) \\
= & \frac{1}{\operatorname{Pr}(D=1 \mid Z=z)} \int_{-\infty}^{z \beta_{D}}\left[\int_{\mathcal{A}(x)} d F_{0,1 \mid D}\left(u_{0}, u_{1} \mid u_{D}\right)\right] d F_{U_{D}}\left(u_{D}\right),
\end{aligned}
$$

and a distributional parameter corresponding to the TT not conditioning on $Z$ for the event $\Delta \in \mathcal{A}$,

$$
\begin{aligned}
& E\left[\mathbf{1}_{\mathcal{A}}(\Delta) \mid X=x, D=1\right] \\
& =\frac{1}{\operatorname{Pr}(D=1 \mid X=x)} \int\left(\int \mathbf{1}_{\left(-\infty, z \beta_{D}\right]}\left(u_{D}\right) \mathbf{1}_{\mathcal{A}}\left(\mu_{1}\left(x, u_{1}\right)-\mu_{0}\left(x, u_{0}\right)\right) d F_{D, 0,1}\left(u_{D}, u_{0}, u_{1}\right)\right) d F_{Z \mid X}(z \mid x) \\
& =\frac{1}{\operatorname{Pr}(D=1 \mid X=x)} \int\left(\int_{-\infty}^{z \beta_{D}}\left[\int_{\mathcal{A}(x)} d F_{0,1 \mid D}\left(u_{0}, u_{1} \mid u_{D}\right)\right] d F_{U_{D}}\left(u_{D}\right)\right) d F_{Z \mid X}(z \mid x) .
\end{aligned}
$$


In the special case where the outcome variable is dichotomous and is generated by an underlying linear latent index, with $\mu_{j}\left(X, U_{j}\right)=\mathbf{1}\left(X \beta_{j} \geq U_{j}\right), Y_{1}$ and $Y_{0}$ are binary and $\Delta$ can take three values. They are

1. $\Delta=1$ if the individual would have a successful outcome if treated (e.g., be employed if trained) and an unsuccessful outcome otherwise. $\left(Y_{0}=0, Y_{1}=1\right)$.

2. $\Delta=0$ if the individual would have a successful outcome in either state $\left(Y_{0}=1, Y_{1}=1\right)$, or the individual would have an unsuccessful outcome in either state $\left(Y_{0}=0, Y_{1}=0\right)$.

3. $\Delta=-1$ if the individual would have a successful outcome if not treated and an unsuccessful outcome if treated. $\left(Y_{0}=1, Y_{1}=0\right)$.

Consider, for example, $\mathcal{A}=\{1\}$, so that $\mathbf{1}_{\mathcal{A}}(\Delta)=\mathbf{1}\left(Y_{0}=0, Y_{1}=1\right)$. In this case, $\mathcal{A}(x)=$ $\left\{\left(u_{0}, u_{1}\right): u_{0}>x \beta_{0}, u_{1} \leq x \beta_{1}\right\}$. We have:

$$
\begin{aligned}
& E\left[1_{\{1\}}(\Delta) \mid X=x\right]=\operatorname{Pr}\left[Y_{1}=1, Y_{0}=0 \mid X=x\right]=\operatorname{Pr}\left[Y_{1}=1 \mid X=x\right] \\
& -\operatorname{Pr}\left[Y_{1}=1, Y_{0}=1 \mid X=x\right]=F_{1}\left(x \beta_{1}\right)-F_{0,1}\left(x \beta_{0}, x \beta_{1}\right)
\end{aligned}
$$




$$
\begin{aligned}
E\left[1_{\{1\}}(\Delta) \mid X=x, Z=z, D=1\right]= & \operatorname{Pr}\left[Y_{1}=1, Y_{0}=0 \mid X=x, Z=z, D=1\right] \\
= & \frac{1}{\operatorname{Pr}[D=1 \mid Z=z]} \operatorname{Pr}\left[Y_{1}=1, Y_{0}=0, D=1 \mid X=x, Z=z\right] \\
= & \frac{1}{\operatorname{Pr}[D=1 \mid Z=z]}\left[\operatorname{Pr}\left[Y_{1}=1, D=1 \mid X=x, Z=z\right]\right. \\
& \left.\quad-\operatorname{Pr}\left[Y_{1}=1, Y_{0}=1, D=1 \mid X=x, Z=z\right]\right] \\
= & \frac{1}{F_{U_{D}}\left(z \beta_{D}\right)}\left[F_{D, 1}\left(z \beta_{D}, x \beta_{1}\right)-F_{D, 0,1}\left(z \beta_{D}, x \beta_{0}, x \beta_{1}\right)\right] \\
E\left[1_{\{1\}}(\Delta) \mid X=x, D=1\right]= & E_{Z}\left[\operatorname{Pr}\left[Y_{1}=1, Y_{0}=0 \mid X=x, Z=z, D=1\right] \mid X=x, D=1\right] \\
= & \frac{1}{E_{Z}\left(F_{U_{D}}\left(Z \beta_{D}\right) \mid X=x\right)} E_{Z}\left[F_{D, 1}\left(Z \beta_{D}, X \beta_{1}\right)\right. \\
= & \operatorname{Pr}\left[Y_{1}=1, Y_{0}=0 \mid X=x, U_{D}=u\right] \\
= & \operatorname{Pr}\left[Y_{1}=1 \mid X=x, U_{D}=u\right]-\operatorname{Pr}\left[Y_{1}=1, Y_{0}=1 \mid X=x, \beta_{D}=u\right] \\
= & F_{1 \mid D}\left(x \beta_{1} \mid z \beta_{D}\right)-F_{0,1 \mid D}\left(x \beta_{0}, x \beta_{1} \mid z \beta_{D}\right) \\
& \operatorname{for} u=Z \beta_{D} .
\end{aligned}
$$

The corresponding parameters for $1_{\{-1\}}(\Delta)$ are defined by straightforward modification of the previous expressions. Notice that

$$
E\left(Y_{1}-Y_{0} \mid X=x\right)=E\left[1_{\{1\}}(\Delta) \mid X=x\right]-E\left[1_{\{-1\}}(\Delta) \mid X=x\right]
$$

so that the average treatment effect is the difference between two corresponding distributional parameters. The average gain $(A T E)$ when outcome variables are binary is the probability of 
being successful (employed) when participating in the program minus the probability of being unsuccessful when participating in the program. Likewise, the other average treatment parameters can be seen as the difference between their corresponding distributional parameters for $1_{\{1\}}(\Delta)$ and $1_{\{-1\}}(\Delta)$. The distributional parameters offer a finer level of detail on the effectiveness of the program.

Identification of the distributional treatment parameters is more difficult than identification of the mean treatment parameters. Thus, identification of the bivariate distribution of $\left(D, Y_{1}\right)$ and $\left(D, Y_{0}\right)$ implies identification of the mean treatment parameters, while identification of the distributional treatment parameters requires knowledge of the full trivariate distribution of $\left(D, Y_{0}, Y_{1}\right)$. Since $Y_{0}$ and $Y_{1}$ are never jointly observed, this trivariate distribution is not identified nonparametrically even when treatment is exogenous. ${ }^{10}$

However, the distribution of treatment effects can be identified if additional assumptions are made. We now discuss one such identifying assumption - that of a factor model. ${ }^{11}$ A more systematic analysis of this assumption appears in Aakvik, Heckman and Vytlacil (1999, Theorem 2). ${ }^{12}$

\footnotetext{
${ }^{10}$ See the discussion in Heckman (1990), Heckman, Smith and Clements (1997) and Heckman and Smith (1998).

${ }^{11} \mathrm{An}$ alternative set of conditions sufficient to identify the full joint distribution $\left(D, Y_{0}, Y_{1}\right)$ when $Y_{0}, Y_{1}$ are continuous involves using the Roy model with sufficient support conditions. See Heckman and Honoré (1990), Heckman (1990) and Heckman and Smith (1998). Aakvik et al (1999) consider how the Roy structure can used to identify the joint distribution in the context of dichotomous $\left(Y_{0}, Y_{1}\right)$.

${ }^{12}$ If the factor structure is imposed, assumption (i) - the existence of an exclusion restriction on observables need not be invoked.
} 


\section{Factor Structure Models}

In our empirical analysis we estimate a three equation model consisting of an equation for the decision rule, an outcome equation for the treated state, and an outcome equation for the non-treated state. The selection outcome and the employment outcomes are discrete. In this paper we specify a discrete-choice, latent-index framework where the unobservables are generated by a normal factor structure. Aakvik et al (1999) consider more general, semiparametric cases. The empirical results produced from the more general framework are in accord with the results reported here.

As before, the decision rule for training is

$$
\begin{aligned}
& D_{i}^{*}=Z_{i} \gamma-U_{D i} \\
& D_{i}=1 \text { if } D_{i}^{*} \geq 0, \quad D_{i}=0 \text { otherwise. }
\end{aligned}
$$

We specify the following employment outcome equation for the training state:

$$
\begin{aligned}
& Y_{1 i}^{*}=X_{i} \beta_{1}-U_{1 i} \\
& Y_{1 i}=1 \text { if } Y_{1 i}^{*} \geq 0, \quad Y_{1 i}=0 \text { otherwise, }
\end{aligned}
$$

and the following employment outcome in the non-treated state

$$
Y_{0 i}^{*}=X_{i} \beta_{0}-U_{0 i}
$$




$$
Y_{0 i}=1 \text { if } Y_{0 i}^{*} \geq 0, \quad Y_{0 i}=0 \text { otherwise. }
$$

We assume that the error terms in equations (9) - (11) are governed by the following factor structure:

$$
\begin{aligned}
U_{D i} & =-\theta_{i}+\epsilon_{D i} \\
U_{1 i} & =-\alpha_{1} \theta_{i}+\epsilon_{1 i} \\
U_{0 i} & =-\alpha_{0} \theta_{i}+\epsilon_{0 i} .
\end{aligned}
$$

The factor structure assumption for discrete choice models was introduced in Heckman (1981) and produces a flexible yet parsimonious specification which yields convenient and easily interpretable expressions for the parameters of interest and at the same time enables us to estimate the model in a tractable fashion.

We assume access to i.i.d. data, and henceforth suppress the $i$ subscript. We make the following normality assumption,

$$
\left(\begin{array}{c}
\theta \\
\epsilon_{D} \\
\epsilon_{1} \\
\epsilon_{0}
\end{array}\right) \sim N(0, I)
$$

where $I$ is the identity matrix and where we have imposed the normalization that $\operatorname{Var}(\theta)=1, \operatorname{Var}\left(\epsilon_{j}\right)=1$ for $j=D, 0,1^{13}$ This normalization is innocuous in the context of a

\footnotetext{
${ }^{13}$ An alternative approach assumes a discrete distribution of $\theta$. In a finite sample, the NPMLE used by Heckman and Singer (1984), is a discrete distribution. See Cameron and Heckman (1987) where models with a discrete factor structure were first developed in the context of a discrete choice model.
} 
normal factor model, see Heckman (1981) or Aakvik et.al. (1999). Let $\Phi$ denote the standard normal CDF and let $\phi$ denote the standard normal probability density function.

The following expressions for the mean treatment parameters in the case of a normal factor model are easily verified:

$$
\begin{aligned}
\Delta^{A T E}(x) & =\int\left[\Phi\left(x \beta_{1}+\alpha_{1} \theta\right)-\Phi\left(x \beta_{0}+\alpha_{0} \theta\right)\right] \phi(\theta) d \theta \\
\Delta^{T T}(x, z, D=1) & =\frac{1}{\Phi\left(\frac{z \beta_{D}}{\sqrt{2}}\right)} \int\left[\Phi\left(x \beta_{1}+\alpha_{1} \theta\right)-\Phi\left(x \beta_{0}+\alpha_{0} \theta\right)\right] \Phi\left(z \beta_{D}+\theta\right) \phi(\theta) d \theta \\
\Delta^{T T}(x, D=1) & =\frac{1}{E\left(\Phi\left(\frac{Z \beta_{D}}{\sqrt{2}}\right) \mid X=x\right)} E_{Z}\left(\int\left[\Phi\left(x \beta_{1}+\alpha_{1} \theta\right)-\Phi\left(x \beta_{0}+\alpha_{0} \theta\right)\right]\right. \\
& \left.\times \Phi\left(Z \beta_{D}+\theta\right) \phi(\theta) d \theta \mid X=x\right) \\
\Delta^{M T E}(x, u) & =\frac{\int\left(\Phi\left(x \beta_{1}+\alpha_{1} \theta\right)-\Phi\left(x \beta_{0}+\alpha_{0} \theta\right)\right) \phi(u+\theta) \phi(\theta) d \theta}{\phi\left(\frac{u}{\sqrt{2}}\right)}
\end{aligned}
$$

Observe that if $\alpha_{1}=\alpha_{0}$, we obtain a common treatment effect (conditional on $X$ ) for the indices of (10) and (11). However, we do not obtain a common treatment effect for the probability of employment gain. Thus note that

$$
\Delta^{A T E}(x)-\Delta^{T T}(x, z, D=1)=\int\left[\Phi\left(x \beta_{1}+\alpha_{1} \theta\right)-\Phi\left(x \beta_{0}+\alpha_{0} \theta\right)\right]\left(1-\frac{\Phi\left(z \beta_{D}+\theta\right)}{\int \Phi\left(z \beta_{D}+\theta\right) \phi(\theta) d \theta}\right) \phi(\theta) d \theta
$$

which will not in general equal zero unless $\alpha_{1}=\alpha_{0}=0$.

The expressions for the distributional treatment parameters are easily derived. For example, the distributional parameters in this case for the event $1\left(Y_{0}=0, Y_{1}=1\right)=1(\Delta=1)$ are:

$$
E[1(\Delta=1) \mid X=x]=\int\left[\Phi\left(x \beta_{1}+\alpha_{1} \theta\right)\left(1-\Phi\left(x \beta_{0}+\alpha_{0} \theta\right)\right)\right] \phi(\theta) d \theta
$$




$$
\begin{aligned}
E[1(\Delta= & 1) \mid X=x, Z=z, D=1] \\
& =\frac{1}{\Phi\left(\frac{z \beta_{D}}{\sqrt{2}}\right)} \int\left[\Phi\left(z \beta_{D}+\theta\right) \Phi\left(x \beta_{1}+\alpha_{1} \theta\right)\left(1-\Phi\left(x \beta_{0}+\alpha_{0} \theta\right)\right)\right] \phi(\theta) d \theta \\
E[1(\Delta= & 1) \mid X=x, D=1]=\frac{1}{E\left(\Phi\left(\frac{Z \beta_{D}}{\sqrt{2}}\right) \mid X=x\right)} E\left[\int \left[\Phi\left(Z \beta_{D}+\theta\right)\right.\right. \\
& \left.\times \Phi\left(x \beta_{1}+\alpha_{1} \theta\right)\left[1-\Phi\left(x \beta_{0}+\alpha_{0} \theta\right)\right] \phi(\theta) d \theta \mid X=x\right] \\
E[1(\Delta= & \left.1) \mid X=x, U_{D}=u\right]=\frac{\int \Phi\left(x \beta_{1}+\alpha_{1} \theta\right)\left(1-\Phi\left(x \beta_{0}+\alpha_{0} \theta\right)\right) \phi(u+\theta) \phi(\theta) d \theta}{\phi\left(\frac{u}{\sqrt{2}}\right)}
\end{aligned}
$$

Observe that the random effects factor model of this section and the matching model of Rosenbaum and Rubin (1983) have a close affinity. If the analyst knew $\theta$, then the matching conditions of Rosenbaum and Rubin (1983) would be satisfied (augmented to account for $Z$ something strictly not required):

$$
\left(Y_{0}, Y_{1}\right) \Perp D \| X, Z, \theta
$$

and

$$
0<\operatorname{Pr}(D=1 \mid X, Z, \theta)<1
$$

where the latter assumption follows from the assumption that $\operatorname{Var}\left(\epsilon_{D}\right)=1$ and normality. ${ }^{14}$ Thus given $\theta$, we could use simple propensity score matching or other standard matching methods to estimate $T T$ and $A T E$. However, matching does not identify $M T E$ or the distributional

\footnotetext{
${ }^{14}$ Under those conditions $\epsilon_{D}$ has full support on the real line.
} 
parameters. $^{15}$

Given that we do not observe $\theta$, this strategy is not available to us. Accordingly, we integrate out $\theta$ assuming that

$$
\theta \Perp(X, Z) .
$$

Thus our random effects set up can be viewed as a solution to a missing conditioning variables problem in matching. ${ }^{16}$

Another approach to the problem of missing conditioning variable is to assume different values of the missing $\theta$ value and to perform a sensitivity analysis. This approach is advocated by Rosenbaum (1995, chapter 5) and implemented in the context of a VR program by Aakvik (1999a). We report estimates obtained from this procedure in Section 6 below.

\section{$5 \quad$ Estimating the Mixture Model}

Conditioning on $\theta$, and restoring the $i$ subscripts, the likelihood for the factor model has the form:

$$
\prod_{i=1}^{N} \operatorname{Pr}\left(D_{i}, Y_{i} \mid X_{i}, Z_{i}, \theta_{i}\right)
$$

\footnotetext{
${ }^{15}$ Heckman and Vytlacil (2000c) develop this point at greater length.

${ }^{16}$ The random effects estimator is a member of the class of control function estimators discussed in Heckman and Vytlacil (2000c).
} 
where

$$
\operatorname{Pr}\left(D_{i}, Y_{i} \mid X_{i}, Z_{i}, \theta_{i}\right)=\operatorname{Pr}\left(D_{i} \mid Z_{i}, \theta_{i}\right) \operatorname{Pr}\left(Y_{i} \mid D_{i}, X_{i}, \theta_{i}\right)
$$

and

$$
\begin{aligned}
\operatorname{Pr}\left(D_{i}=1 \mid Z_{i}, \theta_{i}\right) & =\Phi\left(Z_{i} \beta_{D}+\theta_{i}\right) \\
\operatorname{Pr}\left(Y_{i}=1 \mid D_{i}=1, X_{i}, \theta_{i}\right) & =\operatorname{Pr}\left(Y_{1 i}=1 \mid D_{i}=1, X_{i}, \theta_{i}\right) \\
& =\operatorname{Pr}\left(Y_{1 i}=1 \mid X_{i}, \theta_{i}\right) \\
& =\Phi\left(X_{i} \beta_{1}+\alpha_{1} \theta_{i}\right) \\
\operatorname{Pr}\left(Y_{i}=1 \mid D_{i}=0, X_{i}, \theta_{i}\right) & =\operatorname{Pr}\left(Y_{0 i}=1 \mid D_{i}=0, X_{i}, \theta_{i}\right) \\
& =\operatorname{Pr}\left(Y_{0 i}=1 \mid X_{i}, \theta_{i}\right) \\
& =\Phi\left(X_{i} \beta_{0}+\alpha_{0} \theta_{i}\right) .
\end{aligned}
$$

The likelihood function integrating out $\theta$ has the form:

$$
L=\prod_{i=1}^{N} \int \operatorname{Pr}\left(D_{i}, Y_{i} \mid X_{i}, Z_{i}, \theta\right) \phi(\theta) d \theta
$$

Identification of the parameters of the model, $\left(\beta_{D}, \beta_{0}, \beta_{1}\right)$ and $\left(\alpha_{0}, \alpha_{1}\right)$, follows from the analyses of Heckman (1981) or Aakvik et.al (1999) if $\epsilon_{D}, \epsilon_{0}, \epsilon_{1}$ and $\theta$ are joint normal. We estimate the parameters by maximum likelihood, where we use Gaussian quadrature to approximate the integrated likelihood. ${ }^{17}$

The empirical results reported below are not sensitive to the assumption that $\theta$ is normally

\footnotetext{
${ }^{17}$ See Butler and Moffitt (1982) for a discussion of Gaussian quadrature in this context. We use five evaluation points for the approximation, and we implement the maximum likelihood estimation using the DCPA package of Cameron and Heckman (1987).
} 
distributed. In alternative empirical analyses, we follow Heckman and Singer (1984) and Cameron and Heckman (1987) by approximating the distribution of $\theta$ with a distribution defined on a finite number of support points. ${ }^{18}$ The empirical results obtained from using the discrete mixture model for $\theta$ are similar to the results generated by a normality assumption and for the sake of brevity are not reported.

Given identification of the parameters of the model, all mean and distributional treatment effect parameters are identified and standard errors for the treatment parameters follow from the delta method. We integrate these estimated treatment parameters against the empirical distribution of $X$ and $Z$ to estimate the corresponding treatment parameters integrated over the distribution of $X$ and $Z$. For example, we estimate $E(\Delta)$ by $\frac{1}{N} \sum_{i=1}^{N}\left[F_{U_{1}}\left(X_{i} \beta_{1}\right)-F_{U_{0}}\left(X_{i} \beta_{0}\right)\right]$, where $N$ is the sample size.

The assumption of a one factor structure is crucial to the identification of distributional treatment effect parameters. The one factor structure implies that

$$
\begin{gathered}
\operatorname{Cov}\left(U_{D}, U_{0}\right)=\alpha_{0} \\
\operatorname{Cov}\left(U_{D}, U_{1}\right)=\alpha_{1} \\
\operatorname{Cov}\left(U_{0}, U_{1}\right)=\alpha_{0} \alpha_{1} .
\end{gathered}
$$

(Recall we have scaled the variances of $\epsilon, \epsilon_{0}, \epsilon_{1}$ and $\theta$ all to be one so that the normalizing con-

\footnotetext{
${ }^{18}$ See also Cameron and Taber (1994) for a Monte Carlo analysis of the Cameron-Heckman model.
} 
stants are known). Thus, identification of $\alpha_{0}\left(\operatorname{from} \operatorname{Cov}\left(U_{D}, U_{0}\right)\right)$ and identification of $\alpha_{1}$ (from $\left.\operatorname{Cov}\left(U_{D}, U_{1}\right)\right)$ immediately imply identification of $\operatorname{Cov}\left(U_{0}, U_{1}\right)=\alpha_{0} \alpha_{1}$. Given joint normality, this implies that the joint distribution $U_{D}, U_{0}, U_{1}$ is known. No exclusion restrictions are required (i.e assumption (i) can be relaxed) and a Roy model structure is not required (e.g. $D=1\left(Y_{1} \geq Y_{0}\right)$ or its extension for latent variable models reported in Aakvik et al (1999)).

\section{Data and Institutional Setting}

The Norwegian vocational rehabilitation sector offers income maintenance payments and training programs for individuals whose medical conditions result in reduced productivity. The VR sector has expanded rapidly since the National Social Insurance Act was passed in 1966. The expansion has been guided neither by a firm knowledge on the overall economic impact of the training programs, nor by knowledge of which groups may benefit most from program participation. Today, around 1.5 percent of the labor force participates in a VR training program each day. Most persons who apply for VR job training programs have previously been employed.

Individuals unable to return to work after 52 weeks on sickness benefits are entitled to a VR benefit. The decision to provide the VR benefit is made by the local Social Security Office, usually after a recommendation from a medical doctor. The VR benefit is usually two-thirds of the gross income in the previous year subject to maximum and minimum benefit restrictions. Health status is the legal eligibility criterion for VR benefit.

While receiving a VR benefit, some people return to their old job or obtain disability pensions 
without entering training. Individuals who are not granted a disability pension and do not return to their old job on their own effort are usually referred to the local Employment Office to participate in a job training program. The office evaluates whether training may help applicants obtain a job.

The decision to accept a person into a training program is mainly taken by case workers at the Employment Office and by local managers of vocational rehabilitation centers. This decision is usually based on subjective judgments regarding employment prospects. Main inclusion criteria are health, age, personal characteristics, social conditions, education, and labor force experience. However, the vague criteria for selection and the close connection between the local labor market authorities and local firms and businesses may encourage case workers to select participants based on their expectations of post program employment outcomes rather than on their expectations of post-training effects.

The training programs offered are typically education (classroom training), formal on-the-job training in manufacturing sector firms, and wage subsidies. The training varies in substance and duration across clients. We would expect the training effects to be heterogeneous because training is offered by different institutions. All schooling and labor market training are provided without direct cost for the participants, and participants usually receive a VR benefit while undergoing training. The typical duration of training is 6.5 months.

We have a sample of 1924 individuals who applied for training in 1989, which is a 10 percent random sample of all female VR clients who applied in 1989. Of these applicants, 1,244 were accepted and participated in a training program for at least 5 days. The remaining applicants 
were either not accepted into the training program or were accepted but chose not to participate. ${ }^{19}$ For arguments in favor of "internal" comparison groups, see Bell, Orr, Blomquist and Cain (1995), and Heckman, Ichimura, Smith and Todd (1998). In brief, nonparticipants are located in the same labor market as participants and failure to match within local labor markets has been shown to be an important source of evaluation bias by Heckman, Ichimura, Smith and Todd.

Table 1 contains descriptive statistics of the variables used in our empirical analysis for program participants and nonparticipants. The mean income before clients enter VR is higher for participants both before and after they enter the program. The average age of participants is half a year higher than that of nonparticipants. Furthermore, participants have better education, and they are more likely to hold a job in $1993 .^{20}$

For the observables determining the treatment decision, we use a set of individual background characteristics as well as some variables calculated based on more than 400 municipalities. These administrative areas vary in population (the mean is around 10,000) and geographic area. Our background variables include age, educational level, income, presence of children, age of the youngest child, and work experience. There is a marked difference between the probability of getting day-care placement for children below and above the age of three, and we have constructed a variable to capture this effect. ${ }^{21}$

\footnotetext{
${ }^{19}$ We do not separately observe the case worker's acceptance decision and the decision of the applicant to attend training if accepted.

${ }^{20}$ Employment is defined in this paper as working at least 20 hours per week at the end of our observation period, which is 1993. We have experimented with several different definitions of employment outcomes. For instance, we have used the full-time employed and conditioned on minimum spells of 60 and 90 days in a job in our definition of employment. However, the empirical results are not sensitive to our definition of employment.

${ }^{21}$ Surprisingly, spousal income plays only a minor role in participation decisions and we delete it in the final specifications.
} 
Our instrument $(Z)$ is the degree of rationing. This is calculated as the percentage of applicants in local districts who do not participate in the program. We expect the degree of rationing to influence a person's probability of participating in a training program, but not to affect the employment outcome after training. Unlike training programs for ordinary unemployed people, for which the number of training slots is correlated with the local unemployment rate, the number of slots for VR training programs does not vary due to changes in the unemployment rate in local districts, and instead depends only on the capacity of the local educational sector. Entry into the program is generated by health factors, which are only weakly related to local unemployment rates. The correlation between the degree of rationing variable and local unemployment rate is $.01 .^{22}$ The availability of training slots thus appears to be a valid exclusion restriction.

We take the treatment decision $\left(D_{i}\right)$ to be whether the applicant receives training (is both accepted into training and receives training). ${ }^{23}$ All of our estimated treatment parameters are defined for the population of applicants. Thus, for example, the average treatment effect is the average treatment effect for individuals chosen at random from the pool of applicants, not from the pool of all eligible individuals. We use employment three years after application to training as our outcome measure $\left(Y_{i}\right)$. While we observe employment for each year for three years after application to training, we only use the third year of the data since the employment status is highly correlated across post-application years. Specifying a panel data random coefficient

\footnotetext{
${ }^{22}$ See Aakvik (1999a).

${ }^{23}$ Since the selection process is a joint decision of the case worker and the client, it would be appropriate to follow Poirier (1980) in specifying a multiple index model. Given appropriate exclusion restrictions, our analysis can be extended to allow for a multiple index model of the selection process. We leave this extension to future work.
} 
training model requires special modeling due to the time dependence in outcomes. The required model is a natural extension of the framework developed in this paper. (See Aakvik et al, 2000).

Many evaluation studies use income or wages rather than employment as their outcome measure after training. We use employment rates rather than earnings as our outcome measure for several reasons. First, public expenditure on VR programs is a part of the active labor market policy in Norway. This policy is intended to place as many people as possible into ordinary jobs, since the relatively generous social security system in Norway is likely to fail if high unemployment persists. Second, Norway has a relatively compressed wage distribution. Therefore, wages would not change much due to program participation. Third, LaLonde (1995) and Heckman, LaLonde and Smith (1999) point out that most of the earnings gains reported in the literature in the US follow from higher employment rates rather than from increased wages so an analysis of employment is warranted.

\section{Estimating and Interpreting Mean Treatment Effects and Distributional Treatment Effects}

We now report estimates of the mean treatment parameters based on the factor model presented in Section 4. We first discuss the estimated coefficient values. We then discuss what they imply for the various treatment effects. We then present our analysis of alternative definitions of cream-skimming and our evidence on this issue. Finally we compare our estimates with those obtained from matching and linear instrumental variables methods. The model is estimated by 
maximum likelihood. Using chi-square hit and miss criteria, the model fits the data well. These results are available from the authors on request.

As noted in Section 4, under our normality and factor structure assumptions, no exclusion restrictions or continuous regressors are required to identify the mean or distributional treatment effects. Nonetheless, as noted in Section 6, in our data, we have a plausible exclusion restriction (a variable in $Z$ but not in $X)$ : the degree of rationing. This variable is an important determinant of program participation. If this variable is not used, the fit of the model to the data substantially deteriorates. When the exclusion restriction is used, we can compare our estimates to those produced by an "approximate" instrumental variable analysis of the sort advocated by Angrist $(2000) \cdot{ }^{24}$

\subsection{Estimated Coefficients}

Estimates of the parameters of the selection equation $\left(D^{*}\right)$, the employment equation for nonparticipants $\left(Y_{0}^{*}\right)$, and the employment equation for participants $\left(Y_{1}^{*}\right)$ are reported in Tables 2 and 3, respectively. For each equation, we report the parameter values, the t-values for the parameter values, and the mean marginal effects. ${ }^{25}$

We first discuss the parameters related to selection into training. The estimated parameters of the selection equation reported in Table 2, Column 1 offer insight into the presence of non-

\footnotetext{
${ }^{24} \mathrm{He}$ advocates a linear probability model version of the model fit here regressing $Y$ on $D$, introducing linear controls and instrumenting $D$ by $Z$. The comments by Moffitt (2000) and Todd (2000) criticize this approach.

${ }^{25}$ Let $x_{k}$ and $z_{k}$ denote the $k$ th element of $X$ and $Z$, respectively. The mean marginal effects are defined as the analytical derivatives averaged over the unconditional distribution of either $X$ or $Z$ : $E_{Z}\left(\frac{\partial \operatorname{Pr}(D=1 \mid Z=z)}{\partial z_{k}}\right)$, $E_{X}\left(\frac{\partial \operatorname{Pr}\left(Y_{0}=1 \mid X=x\right)}{\partial x_{k}}\right)$, and $E_{X}\left(\frac{\partial \operatorname{Pr}\left(Y_{1}=1 \mid X=x\right)}{\partial x_{k}}\right)$.
} 
random selection into rehabilitation programs. Individuals participating in the program differ significantly from eligible nonparticipants with respect to observable characteristics. If a potential participant had favorable characteristics associated with higher employment in either the trained or the untrained state before VR began, such as being young, having no children and being welleducated, then he or she has a greater probability of participating in a training program. Given the presence of children, persons with older children are more likely to participate in a training program. The coefficient on the degree of rationing in local districts is significantly different from zero.

Next turn to the employment equations. We report the estimated employment regression coefficients in Table 3 , where the $\beta_{0}$-vector is reported in column 1 of Table 3 , and the $\beta_{1}$ vector is reported in column three of Table 3. For both employment equations, all the estimated coefficients have reasonable signs and most of them are statistically significant. Young individuals with high education, no children, high working experience, and high previous income have the best chances of being employed at the end of our observation period. Young children decrease the probability of employment.

We also estimate the same model with the restriction that all factor loadings $\left(\alpha_{0}, \alpha_{1}\right)$ equal zero. Fixing the factor loadings to zero imposes that the error terms are independent across equations, and thus does not allow for selection on unobservables related to the employment equations. The resulting estimates of the slope coefficients are similar to those reported in these tables when more general models with factor loadings are estimated. However, as discussed below in Section 7.6, imposing that the error terms are independent across equations results in a dramatic change in 
the estimated treatment parameter values. ${ }^{26}$ Moreover, the fit of the model to the data is slightly worse when we impose that the error terms are independent across equations. In this sense, a model with unobservables on which agents select is more consistent with the data.

However, both likelihood ratio tests and $t$ statistics on the factor loadings evaluated at conventional levels do not reject the null hypothesis of no selection bias due to unobservables. However, the estimated factor loadings are large, even if imprecisely estimated.

In this paper we proceed conditional on the estimated non zero values of $\alpha$. We are reluctant to set a large $\alpha_{j}$ to zero using a pretest estimator. Even if the reader wishes to set the $\alpha_{j}$ to zero based on the reported test statistics, the analysis that follows can be taken as an illustration of how to estimate a variety of interesting mean and distributional parameters if selection on unobservables is an empirically important phenomenon.

\subsection{Estimated Mean Treatment Parameters}

We next compute the different mean treatment parameters conditional on the maximum likelihood values for all of the parameters. We find that

$$
\begin{gathered}
A T E \equiv E(\Delta)=-0.014 \\
T T \equiv E(\Delta \mid D=1)=-0.11 .
\end{gathered}
$$

\footnotetext{
${ }^{26}$ The slope estimates with the factor loadings fixed to zero are available upon request from the authors.
} 
For the entire population, the program has a slight negative effect, but has a stronger negative effect for those who are selected into the program. This suggests that selection into the program is perverse on net gains, a point we develop below in Section 7.5. In comparison, as reported in Table 1, the raw difference in mean outcomes is .046 $\left.\left(E\left(Y_{1} \mid D=1\right)-E\left(Y_{0} \mid D=0\right)=.046\right)\right)$. Thus controlling for selection appears to be very important in these data.

In order to study the relationship between unobservable characteristics related to program participation and the treatment effect, we plot the estimated $M T E$ parameter for different values of $U_{D}$. (See Figure 1). The $M T E$ parameter is increasing in $U_{D}$. It is negative for $U_{D}$ values below .2 while it is large and positive for large $U_{D}$ values. Recall that higher values of $U_{D}$ imply lower probabilities in the program. Thus, in terms of unobservables, those most likely to participate benefit the least from the program. This evidence is consistent with our estimates for $A T E$ and for the effect of treatment on the treated. From the analysis of Heckman and Vytlacil (2000a,b,c), and from equation (8), the effect of treatment on the treated is an integrated version of $M T E$ with most of the weight being placed on $M T E$ values with $U_{D}$ values small (where the estimated value of $M T E$ is very negative). ATE weights $M T E$ more uniformly and accordingly is larger.

\subsection{Heterogeneity in Observables}

The estimated treatment effects vary substantially with observed characteristics. For example, the variance of $E(\Delta \mid X)$ is .014, compared to its mean of -0.014 . The variance of $E(\Delta \mid X, D=1)$ is .014 compared to its mean of -0.11 . The degree to which the treatment effects varies with observable characteristics can also be seen by studying the marginal effect of each observable 
characteristic on the expected treatment effect. The marginal effects on the treatment parameters are reported in Table 4. For example, being older, having lower pre program income, having lower spouse's income, and having young children are all associated with a larger treatment effect for all definitions of mean treatment effects. We develop this point further after we analyze distributional treatment parameters.

\subsection{Estimated Distributional Treatment Parameters}

The distributional treatment effect parameters capture an additional type of treatment effect heterogeneity beyond that previously discussed for mean treatment effects. We now report estimates of the distributional treatment parameters. Table 5 reports the distributional versions of $A T E, T T$, and $M T E$ evaluated at selected values of $U_{D}$. We find that if a random applicant is assigned to training, with probability .225 the applicant benefits from the training, that is, will be employed after receiving the training but would have been unemployed without the training. However, with probability .24 the applicant will be hurt by receiving the training, being unemployed after receiving the training but employed without receiving the training. The mean parameter for $A T E,-0.014$, masks the underlying heterogeneity that nearly a quarter of all individuals become employed as a consequence of participating in the program and nearly a quarter of all individuals who participate become unemployed. The impact of the program is most negative for those most likely to enter the program. For example, the estimated $M T E$ parameter evaluated at $U_{D}=-2$ shows that only $11.9 \%$ of such agents become employed because of participation but $37.3 \%$ of such agents become unemployed because of the program. These numbers are reversed for those 
least likely to enter the program (high values of $U_{D}$ ). The $M T E$ parameter evaluated at $U_{D}=2$ finds $35 \%$ of agents with $U_{D}=2$ become employed because of participation and only $12.6 \%$ of such agents become unemployed due to participation in the program. As a consequence of our index model, we can write $\operatorname{Pr}(\Delta=1 \mid X)=\operatorname{Pr}\left(\Delta=1 \mid X \beta_{1}, X \beta_{0}\right)$ so that two indices capture the full $X$ effect on $\operatorname{Pr}(\Delta=1 \mid X)$. Figure 2 graphs this function against quantiles of $X \beta_{1}$ and $X \beta_{0}$. Figures 3 and 4 are the corresponding graphs for $\operatorname{Pr}\left(\Delta=0 \mid X \beta_{1}, X \beta_{0}\right)$ and $\operatorname{Pr}\left(\Delta=-1 \mid X \beta_{1}, X \beta_{0}\right)$ respectively. The greatest gains in employment are for those with the highest index for employment in the treated state and the lowest employment index for the untreated state. The graph for $\operatorname{Pr}\left(\Delta=-1 \mid X \beta_{1}, X \beta_{0}\right)$ is the mirror image of Figure 2. The graph for $\operatorname{Pr}\left(D=0 \mid X \beta_{1}, X \beta_{0}\right)$ shows that persons with balanced levels of indices are the ones most likely to be unaffected by the program $(\Delta=0)$. There is considerable heterogeneity in response to the program among persons with different $X$ values.

\subsection{Cream-Skimming: The Relationship Between Selection Into the Program and Outcomes}

A central question in the analysis of a program like VR is whether those who benefit the most from it are those most likely to participate in it. We have already noted that $A T E$ is greater than $T T$ i.e., that randomly selected persons benefit more from the program than those who participate in it. This suggests that the combination of $U_{D}$ and $Z$ values that promote program participation are perversely associated with the observed and unobserved factors associated with 
gains from the program.

In order to determine the extent of cream-skimming on both observables and unobservables, it is necessary to relate $\Delta$ (as defined by the various means and distributional parameter analogues) to $Z \beta_{D}$ and $U_{D}$. We have estimated relationships among $\Delta$ and $\left(X \beta_{1}, X \beta_{0}, U_{1}, U_{0}\right)$, however. So the problem is how to go from the relationships we have estimated to determine the relationships between gains and $Z \beta_{D}$ and $U_{D}$.

Given the factor structure model, we can easily determine how variation in $U_{D}$ affects $U_{1}$ and $U_{0}$ (see equation (12)). By virtue of independence assumption (iii), the factor relationship does not depend on values of $Z \beta_{D}, X \beta_{1}$ and $X \beta_{0}$. We have used this relationship in computing Figure 1 and in inferring that selection into the program is perverse in terms of unobservables. Another way to make the same point is to inspect the correlations among the unobservables. Using our normalizations

$$
\begin{aligned}
& \operatorname{Corr}\left(U_{0}, U_{1}\right)=\frac{\alpha_{0} \alpha_{1}}{\sqrt{1+\alpha_{0}^{2}} \sqrt{1+\alpha_{1}^{2}}}=-.116 \\
& \operatorname{Corr}\left(U_{D}, U_{0}\right)=\frac{\alpha_{0}}{\sqrt{2} \sqrt{1+\alpha_{0}^{2}}}=.281 \\
& \operatorname{Corr}\left(U_{D}, U_{1}\right)=\frac{\alpha_{1}}{\sqrt{2} \sqrt{1+\alpha_{1}^{2}}}=-.208
\end{aligned}
$$

From the latter two correlations, the unobservables that promote participation are positively correlated with the unobservables that promote employment in the no-training state but are negatively correlated with the unobservables that promote employment in the training state. 
Thus higher $U_{D}$ is associated with higher $U_{0}$ and lower $U_{1}$ so that persons with low values of $U_{D}$ (who are more likely to participate in the program) are more likely to have lower values of $\Delta$, holding constant $X$ and $Z$. Hence, selection is perverse on unobservables: treatment effects are the lowest for those most likely to participate.

The harder problem is to determine the effect of $Z \beta_{D}$ on $\Delta$. The obvious way to assess this dependence is to estimate our model nonparametrically, determining the relationship between objects like $A T E$ and Treatment on the Treated on $Z \beta_{D}$. A completely general way to express $A T E$ in terms of $Z \beta_{D}$ writes

$$
E\left(\Delta \mid Z \beta_{D}\right)=E_{Z \beta_{D}}[E(\Delta \mid X)]=\int E\left(Y_{1}-Y_{0} \mid X=x\right) d F\left(x \mid Z \beta_{D}\right) .
$$

A comparable expression can be derived for $E\left(\Delta \mid Z \beta_{D}, D=1\right)$ the $T T$ parameter:

$$
\begin{aligned}
& E\left(\Delta \mid Z \beta_{D}=z \beta_{D}, D=1\right) \\
& =\int E\left(Y_{1}-Y_{0} \mid X=x, Z \beta_{D}=z \beta_{D}, D=1\right) d F\left(x \mid D=1, Z \beta_{D}=z \beta_{D}\right)
\end{aligned}
$$

To estimate these expressions requires determining the distributions of $F\left(x \mid Z \beta_{D}=z \beta_{D}\right)$ and $F\left(x \mid Z \beta_{D}=z \beta_{D}, D=1\right)$. The effect of the $X$ can be reduced to the effect of two scalars, $\left(X \beta_{1}, X \beta_{0}\right)$, by virtue of our index assumption. To estimate these densities requires nonparametric estimation of bivariate densities, a task we leave for another occasion.

Instead, we examine the dependence among the indices $\left(Z \beta_{D}, X \beta_{0}, X \beta_{1}\right)$ using correlations. We view this analysis as a prelude to a full nonparametric analysis. Many of the same characteristics that predict employment in the nonparticipation state also predict employment in the 
participation state. Also, many of the same characteristics that predict participation in training also predict higher employment probabilities for both the participation and nonparticipation outcome equations. We estimate the following correlations across the indices of these equations:

$$
\begin{aligned}
& \operatorname{Corr}\left(X \beta_{0}, X \beta_{1}\right)=0.81 \\
& \operatorname{Corr}\left(Z \beta_{D}, X \beta_{0}\right)=0.42 \\
& \operatorname{Corr}\left(Z \beta_{D}, X \beta_{1}\right)=0.27 .
\end{aligned}
$$

The indices are all positively correlated with each one another. Thus, unlike the case that arises in our analysis of unobservables, a higher index for participation is associated with higher employment outcomes in both the treated and untreated states and the effect on $\Delta$ depends on the levels at which the indices are related. Note that the correlation between $X \beta_{1}$ and $X \beta_{0}$ is strong and positive but they are not perfectly correlated. There is a strong relationship between observable characteristics that predict participation and observable characteristics that predict employment in the non-participation state. $\operatorname{Corr}\left(Z \beta_{D}, X \beta_{0}\right)=0.43$. The correlations in the indices induce very similar correlations in the fitted probabilities:

$$
\begin{aligned}
& \operatorname{Corr}\left(\operatorname{Pr}\left(Y_{1}=1 \mid X\right), \operatorname{Pr}\left(Y_{0}=1 \mid X\right)\right)=0.81 \\
& \operatorname{Corr}\left(\operatorname{Pr}(D=1 \mid Z), \operatorname{Pr}\left(Y_{0}=1 \mid X\right)\right)=0.42 \\
& \operatorname{Corr}\left(\operatorname{Pr}(D=1 \mid Z), \operatorname{Pr}\left(Y_{1}=1 \mid X\right)\right)=0.27
\end{aligned}
$$


The correlations combining both the observable and unobservable components of the indices are:

$$
\begin{aligned}
& \operatorname{Corr}\left(Y_{1}^{*}, Y_{0}^{*}\right)=\operatorname{Corr}\left(X \beta_{1}+U_{1}, X \beta_{0}+U_{0}\right)=0.05 \\
& \operatorname{Corr}\left(D^{*}, Y_{0}^{*}\right)=\operatorname{Corr}\left(Z \beta_{D}+U_{D}, X \beta_{0}+U_{0}\right)=0.31 \\
& \operatorname{Corr}\left(D^{*}, Y_{1}^{*}\right)=\operatorname{Corr}\left(Z \beta_{D}+U_{D}, X \beta_{1}+U_{1}\right)=-0.14
\end{aligned}
$$

Note that the correlation between the latent index for participation and the latent index for employment in the nonparticipation state is even higher than the correlation between the indices for employment in the participation and nonparticipation states.

The difference between the mean outcomes and the selection-corrected mean outcomes is consistent with the evidence just discussed. In particular, individuals who are most likely enter the program are those who are most likely to be employed. In addition, those with the characteristics that make them most likely to participate are the ones who benefit the least from the program. This is true both for the observed characteristics and the unobserved characteristics. In terms of observed characteristics, note that

$$
\operatorname{Corr}\left(Z \beta_{D}, X\left(\beta_{1}-\beta_{0}\right)\right)=-0.41
$$

which induces a similar correlation between the fitted probabilities of participation and the ex- 
pected treatment effect,

$$
\operatorname{Corr}(\operatorname{Pr}(D=1 \mid Z), E(\Delta \mid X))=\operatorname{Corr}\left(\operatorname{Pr}(D=1 \mid Z), \operatorname{Pr}\left(Y_{1}=1 \mid X\right)-\operatorname{Pr}\left(Y_{0}=1 \mid X\right)\right)=-0.38
$$

In terms of unobserved characteristics,

$$
\operatorname{Corr}\left(U_{D}, U_{1}-U_{0}\right)=-0.33
$$

The correlation in the observables and unobservables reinforce one another, resulting in

$$
\operatorname{Corr}\left(D^{*}, Y_{1}^{*}-Y_{0}^{*}\right)=-0.33 \text {. }
$$

This analysis demonstrates that those most likely to participate in the program are those who benefit the least from it. Contrary to several US studies which find that persons with characteristics associated with better labor market outcomes also gain the most from training (see the studies summarized in Heckman, LaLonde and Smith (1999)) we find that characteristics associated with better labor market outcomes are negatively correlated with training effects.

The overall effectiveness of VR training programs in terms of producing employment gains can be improved by changing the selection criteria for participating in training. By focusing on selecting persons with a high training effect, the mean effect of VR training can be improved, although the gross employment outcomes among participants may be reduced. ${ }^{27}$

\footnotetext{
${ }^{27}$ We lack information on costs. Thus the net social benefit of our proposed change in the strategy of selection
} 


\subsection{Comparison with Results Using Other Estimation Methods}

In Table 6, we compare our estimated treatment parameters with the estimates produced from alternative estimators. In particular, we compare our estimated ATE and TT parameters with the estimates resulting from: (1) mean difference in outcomes between participants and nonparticipants (i.e., assuming treatment is exogenous); (2) estimation by matching on observables, using the analysis of Aakvik (1999b), (3) estimating our latent index model but with the factor loadings set to zero; (4) estimating our model using normal heterogeneity; (5) estimation by linear IV, where we impose a linear probability model form for the outcome equation assuming that treatment only shifts the intercepts of the outcome equations, and use the estimated $\operatorname{Pr}[D=1 \mid Z]$ as the instrument for $D$; (6) estimation by linear IV, following Angrist (2000), where we impose a linear probability model form for the outcome equation, allow the treatment effect to vary with observable variables, and use the estimated $\operatorname{Pr}[D=1 \mid Z] \times X$ as the instrument for $D X$. Note that each of these estimators is based on different identifying assumptions. (See Heckman and Vytlacil, 2000c, for a discussion of these assumptions).

Notice the following features of Table 6. First, the raw difference in mean outcomes is substantially higher than the estimated $A T E$ or $T T$ from any of the other estimators. Second, controlling for unobservables appears to be important. The estimators that allow for selection on unobservables all produce estimates of $T T$ that are substantially lower than the estimates produced by estimators that assume no selection on unobservables like the IV estimators. However, for $A T E$

may be negative. See Heckman and Smith (1998) for evidence on the importance of accounting for full social costs in evaluating social programs. 
the two types of estimators are in closer agreement. Third, for each estimator that allows ATE and $T T$ to be distinct, it is always the case that $T T$ is lower than $A T E$.

\section{Placing Our Empirical Results in the Literature on VR}

\section{Programs}

The literature on vocational rehabilitation programs reports no estimates of training effects based on randomized experiments. The literature on manpower programs directed towards the unemployed contains both methodological and empirical discussions of the relative merits of experimental and non-experimental evaluation methods. ${ }^{28}$

Methodologically, the problems of evaluating manpower and VR training programs are quite similar. However, it is not clear that the empirical regularities in the manpower literature apply to VR programs because participants in VR training programs have health problems that distinguish them from healthy individuals who are unemployed.

Very few studies of the effects of VR training control for potentially successful rehabilitation without training at all. In a review of the literature analyzing US data, Worrall (1988) focuses on this shortcoming. He notes that all the studies that he reviews are hampered by the lack of a control group. Nevertheless, other researchers have attempted to draw some inference from the same literature that Worrall reviews. Haveman, Halberstadt and Burkhauser (1984) offer a

\footnotetext{
${ }^{28}$ See, e.g., Heckman and Hotz (1989), Burtless (1995), Heckman and Smith(1995), LaLonde (1995), and Heckman, LaLonde and Smith (1999).
} 
guarded assessment, stating that concentrating rehabilitation activities on younger, less disabled, and more productive workers appears to be more efficient in promoting employment than focusing on disabled workers with the most severe handicaps.

Nowak (1983) and Dean and Dolan (1991) analyze the effects of VR programs in the US using a comparison group approach. Both these analyses find evidence that suggests a difference between gross success rates and training effects. Both studies report that females benefit more from training than males. ${ }^{29}$ In results available on request from the authors, gender effects in Norwegian VR training programs are opposite to those found in the United States: estimated training effects are higher for males. We also find a statistically significant selection of young, relatively highly educated individuals with long work experience and no children into training programs. These individuals have a significantly higher probability of employment, with or without the treatment. Other characteristics that are predictive of a significant and positive effect on employment rates include high yearly pre-program income and high yearly spousal income. Thus, as noted in Section 6, program managers select participants so as to maximize gross employment rates among participants in training programs.

Our analysis suggests that a different selection rule would increase the overall efficacy of training in promoting gains in employment assuming that the costs are the same across different selection rules. By concentrating on older, less educated women with low levels of work experience, there would be a drop in their recorded employment rates, but an increase in employment

\footnotetext{
${ }^{29}$ Similar results are found in several other training program evaluations, see the reviews by Barnow (1987), Gueron and Pauly (1991), LaLonde (1995), and Heckman, LaLonde and Smith (1999). Typically, they find that training has a significant effect for women, and that there are no significant effects for men and youths in terms of increased employment rates and wages. These results apply both for experimental and for observational studies.
} 
attributable to the program.

\section{Summary, Conclusions and Related Work}

This paper formulates an econometric framework for studying treatment effects on discrete outcomes when the treatment effects vary among observationally identical persons. Using a latent variable framework, we show how to define and estimate the average treatment effect, the effect of treatment on the treated, and the marginal treatment effect on discrete outcomes. We also develop and estimate distributional analogues to these parameters. To secure estimates, we assume a factor-structure assumption for the model unobservables.

In related research, we relax the parametric normal assumptions used in this paper to construct semiparametric mean and distributional parameters. We present formal proofs of identification and a sampling theory for the semiparametric estimators considered in that paper. In Aakvik et.al. (2000), we extend both the parametric and semiparametric analyses of this paper to consider treatment effects in a structural duration model.

The Norwegian VR we study offers different general and specific training programs at different locations to a diverse population. The estimated effects of these training programs vary both in terms of observed and unobserved factors. In particular, training effects are larger for individuals with characteristics that predict lower employment in either the trained or untrained state. Cream-skimming of individuals into training on the basis of characteristics that are positively associated with employment is less effective in promoting employment gains than randomly 
selecting participants from the pool of applicants. There is a potential for improving the overall employment-promoting effect of VR training by selecting those who gain the most from training rather than choosing more employable persons.

Governmental evaluations of training programs in most countries typically are based on postprogram outcome measures. Such an evaluation strategy gives caseworkers an incentive to select the most employable for training. Caseworkers are seldomly able to estimate treatment effects. Thus guidance on who should participate should be based on results from research rather than by rules-of-thumb. We find that the employment gains in the Norwegian VR program will be enhanced if the selection rule is changed to encourage the least employable to participate. 


\section{References}

[1] Aakvik, A., 1999a, "Five Essays on the Microeconometric Evaluation of Job Training Programs," Dissertation, University of Bergen.

[2] Aakvik, A., 1999b, "Bounding a Matching Estimator: The Case of a Norwegian Training Program," working paper, University of Bergen.

[3] Aakvik, A., J. Heckman and E. Vytlacil 1999, "Semiparametric Program Evaluation: Lesson from an Evaluation of a Norwegian Training Program," unpublished manuscript, University of Chicago.

[4] ____, "Estimating a Latent Variable Duration Model with An Application To Health Economics," unpublished manuscript, University of Chicago, 2000.

[5] Angrist, J., 2000. "Estimation of Limited Dependent Variables with Binary Endogenous Regressors: Simple Strategies for Empirical Practice," Journal of Economics and Business Statistics, (see also discussions by Moffitt and Todd).

[6] Angrist, J., K. Graddy, and G. Imbens, 1995, "Non-Parametric Demand Analysis with an Application to the Demand for Fish," NBER working paper No. T0178.

[7] Barnow, B., 1987, "The Impact of CETA Programs on Earnings: A Review of the Literature," Journal of Human Resources, 22, 157-193. 
[8] Bell, S., L. Orr, J. Blomquist, and G. Cain, 1995, Program Applicants as a Comparison Group in Evaluating Training Programs, W. E. Upjohn Institute for Employment Research, Kalamazoo, Michigan.

[9] Björklund, A. and R. Moffitt, 1987, "The Estimation of Wage Gains and Welfare Gains in Self-Selection Models," Review of Economics and Statistics, 69, 42-49.

[10] Burtless, G., 1995, "The case for randomized field trials in economic and policy research", Journal of Economic Perspectives 9(2), 63-84.

[11] Butler, J. and R. Moffitt, 1982, "A Computationally Efficient Quadrature Procedure for the One Factor Multinomial Probit Model, "Econometrica, 50, 761-764.

[12] Cameron, S. and J. Heckman, 1987, "Son of CTM: The DCPA Approach Based on Discrete Factor Structure Models," working paper, University of Chicago.

[13]___, 1998, "Life Cycle Schooling and Dynamic Selection Bias," Journal of Political Economy 106, 262-333.

[14] Cameron, S. and C. Taber, 1994, "Evaluation and Identification of Semiparametric Maximum Likelihood Models of Dynamic Discrete Choice," working paper, University of Chicago.

[15] Card, D. and D. Sullivan, 1988, "Measuring the Effect of Subsidized Training Programs on Movements In and Out of Employment," Econometrica, 56, 497-530. 
[16] Chen, Xiaohong, J. Heckman and E. Vytlacil, 1999, "Identification and $\sqrt{N}$ Efficient Estimation of Semiparametric Panel Data Models with Binary Dependent Variables and a Latent Factor," Working paper, University of Chicago, Department of Economics.

[17] Cox, D. R., 1958, The Planning of Experiments, (New York: Wiley).

[18] Dean, D. and R. Dolan, 1991, "Fixed-Effects Estimates of Earnings Impacts for the Vocational Rehabilitation Program," Journal of Human Resources, 26, 380-391.

[19] Fisher, R. A., 1935, Design of Experiments, (London: Oliver and Boyd).

[20] Gay, R. and M. Borus, 1980, "Validating Performance Indicators for Employment and Training Programs," Journal of Human Resources, 15, 29-48.

[21] Gritz, M., 1993, "The Impact of Training on the Frequency and Duration of Employment," Journal of Econometrics, 57, 21-51.

[22] Gueron, J. and Pauly, E., 1991, From Welfare to Work, (New York, Russell Sage Foundation).

[23] Ham, J. and R. Lalonde, 1996, "The Effects of Sample Selection and Initial Conditions in Duration Models: Evidence from Experimental Data on Training," Econometrica, 64, 175205.

[24] Haveman, R., V. Halberstadt, and R. Burkhauser, 1984, Public Policy Towards Disabled Workers: Cross-National Analyses of Economic Impacts, (Cornell University Press, Itacha). 
[25] Heckman, J. 1981, "Statistical Models For Discrete Panel Data," in: C. Manski and D. McFadden, eds., Structural Analysis of Discrete Data with Econometric Applications. M.I.T. Press.

[26] ____,1990, "Varieties of Selection Bias," American Economic Review, 80, 313-318.

[27] ____, 1992, "Randomization and Social Program Evaluation," in: C. Manski and I. Garfinkle, eds. Evaluating Welfare and Training Program, (Harvard University Press), 201-230.

[28] ____, 1997, "Instrumental Variables: A Study of Implicit Behavioral Assumptions Used in Making Program Evaluations," Journal of Human Resources 32, 441-462.

[29] Heckman, J. and B. Honoré, 1990, "The Empirical Content of the Roy Model," Econometrica 58, 1121-1149.

[30] Heckman, J. and J. Hotz, 1989, "Choosing Among Alternative Methods of Estimating the Impact of Social Programs: The Case of Manpower Training," Journal of the American Statistical Association, 84, 862-874.

[31] Heckman, J., Ichimura, H., Smith, J., and P. Todd, 1998, "Characterizing Selection Bias Using Experimental Data," Econometrica, 66, 1017-1098.

[32] Heckman, J., R. LaLonde, and J. Smith, 1999, "The Economics and Econometrics of Training Programs," forthcoming in: O. Ashenfelter and D. Card, eds., Handbook of Labor Economics, Volume III, (North Holland, Amsterdam). 
[33] Heckman, J., L. Lochner, and C. Taber, 1998a, "Explaining Rising Wage Inequality: Explorations with a Dynamic General Equilibrium Model of Labor Earnings with Heterogeneous Agents," Review of Economic Dynamics, 1(1), 1-58.

[34] ____, 1998b, "General Equilibrium Treatment Effects: A Study of Tuition Policy," American Economic Review, 88(2), 381-386.

[35] Heckman, J. and R. Robb, 1985, "Alternative Methods for Evaluating the Impact of Interventions," in: J. Heckman and B. Singer, eds., Longitudinal Analysis of Labor Market Data, (Cambridge University Press, New York) 156-245.

[36] Heckman, J. and B. Singer, 1984, "A Method for Minimizing the Impact of Distributional Assumptions in Econometric Models for Duration Models," Econometrica, 52, 271-320.

[37] Heckman, J. and J. Smith, 1995, "Assessing the Case for Social Experiments," Journal of Economic Perspectives, 9, 85-100.

[38] ____, 1998, "Evaluating the Welfare State," in: S. Strom, ed., Econometrics and Economic Theory in the 20th Century: The Ragnar Frisch Centennial, Econometric Society Monograph Series, (Cambridge: Cambridge University Press).

[39] Heckman, J., J. Smith, and N. Clements, 1997, "Social Experiments: Accounting for Heterogeneity in Programme Impacts," Review of Economic Studies, 64, 487-535. 
[40] Heckman, J. and E. Vytlacil, 1999, "Local Instrumental Variables and Latent Variable Models for Identifying and Bounding Treatment Effects," Proceedings of the National Academy of Sciences, 96, 4730-4734.

[41] ____, 2000a, "The Relationship Between Treatment Parameters within a Latent Variable Framework," Economic Letters, 66, 33-39.

[42] ___, 2000b, "Local Instrumental Variables," in: C. Hsiao, K. Morimune, and J. Powell , eds., Nonlinear Statistical Inference: Essays in Honor of Takeshi Amemiya, (Cambridge University Press: Cambridge), forthcoming.

[43] ___, 2000c, "Econometric Evaluations of Social Programs," forthcoming in: J. Heckman and E. Leamer, eds., Handbook of Econometrics, Volume 5, (North-Holland: Amsterdam).

[44] Imbens, G. and J. Angrist, 1994, "Identification and Estimation of Local Average Treatment Effects," Econometrica 62, 467-476.

[45] Junker, B., and Ellis, J., 1997, "A Characterization of Monotone Unidimensional Latent Variable Models," Annals of Statistics, 25, 1327-1343.

[46] LaLonde, R., 1995, "The Promise of Public Sector-Sponsored Training Programs," Journal of Economic Perspectives 9, 149-168.

[47] Lewis, H. G., 1963, Unionism and Relative Wages, (Chicago: University of Chicago Press).

[48] Maddala, G. S., 1983, Limited-Dependent and Qualitative Variables in Econometrics, (Cambridge: Cambridge University Press). 
[49] Moffitt, R., 2000, "Comment on: Estimation of Limited Dependent Variables with Binary Endogenous Regressors: Simple Strategies for Empirical Practice," Journal of Economics and Business Statistics.

[50] Neyman, J., 1923, "Statistical Problems in Agricultural Experiments," Supplement to the Journal of the Royal Statistical Society 2(2), 107-180.

[51] Nowak, L., 1983, "A Cost Effectiveness Evaluation of the Federal/State Vocational Rehabilitation Program - Using a Comparison Group," The American Economist, 27, 23-29.

[52] Poirier, D., 1980, "Partial Observability in Bivariate Probit Models," Journal of Econometrics, 12, 209-17.

[53] Quandt, R., 1972, "Methods for Estimating Switching Regressions," Journal of the American Statistical Association, 67(338), 306- 310.

[54] Ridder, G., 1986. "An Event History Approach to the Evaluation of Training, Recruitment and Employment Programmes," Journal of Applied Econometrics, 1, 109-126.

[55] Rosenbaum, P., 1995, Observational Studies, (Berlin: Springer Verlag).

[56] Rosenbaum, P. and Rubin, D., 1983, "The Central Role of the Propensity Score in Observational Studies for Causal Effects," Biometrika, 70, 41-55.

[57] Roy, A., 1951, "Some Thoughts on the Distribution of Earnings," Oxford Economic Papers, 3, 135-146. 
[58] Rubin, D., 1978, "Bayesian Inference for Causal Effects: The Role of Randomization," Annals of Statistics, 6, 34-58.

[59] Todd, P., 2000, "Comment on: Estimation of Limited Dependent Variables with Binary Endogenous Regressors: Simple Strategies for Empirical Practice," Journal of Economics and Business Statistics.

[60] Vytlacil, E., 2000, "Independence, Monotonicity, and Latent Variable Models: An Equivalence Result," working paper, University of Chicago.

[61] Worrall, J., 1988, "Benefit and Cost Models," in: E. Berkowitz, ed., Measuring the Efficiency of Public Programs. Costs and Benefits in Vocational Rehabilitation, (Temple University Press), 45-62. 


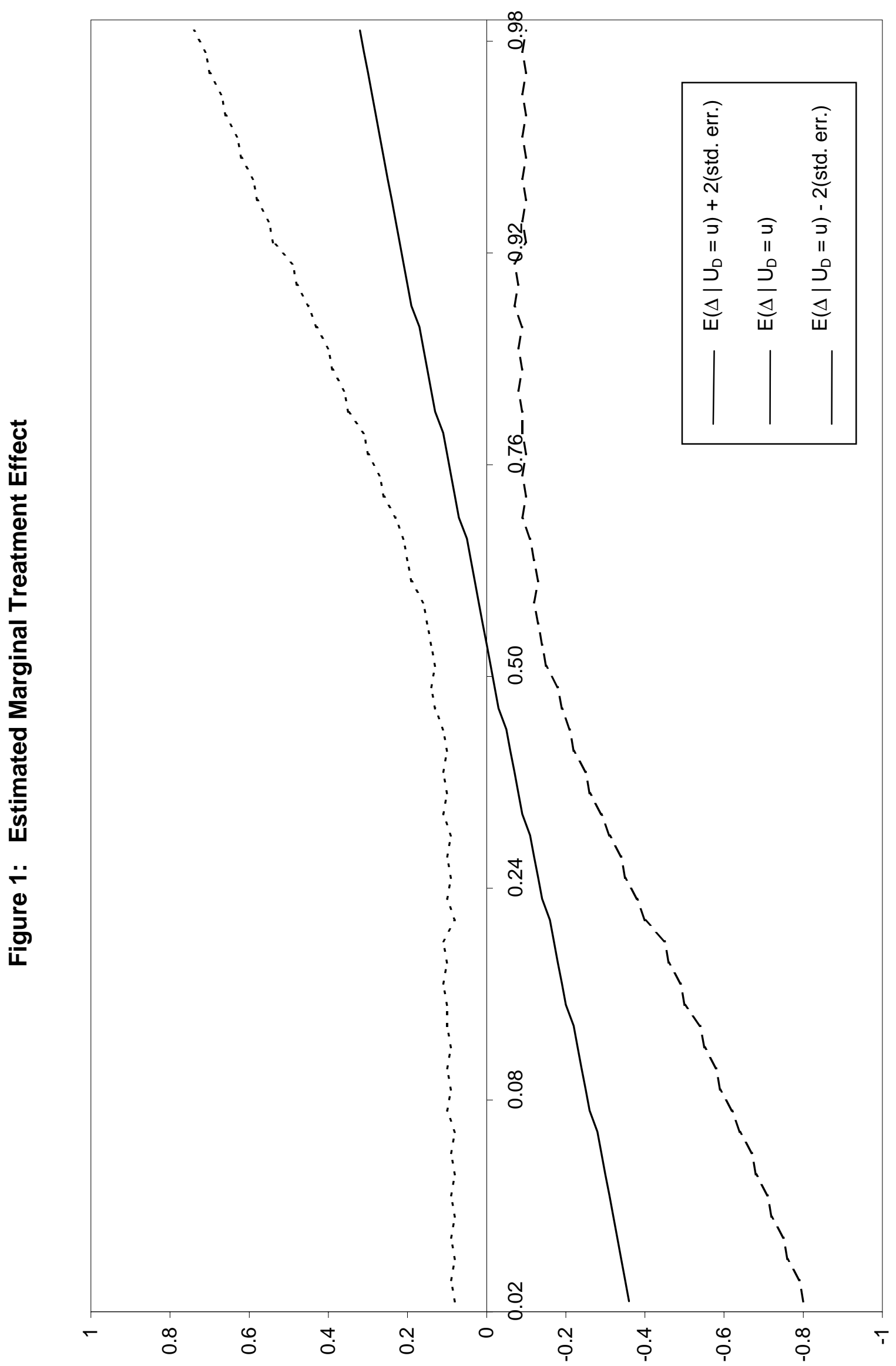


Figure 2: Prob(Delta=1|Xb1, Xb0)

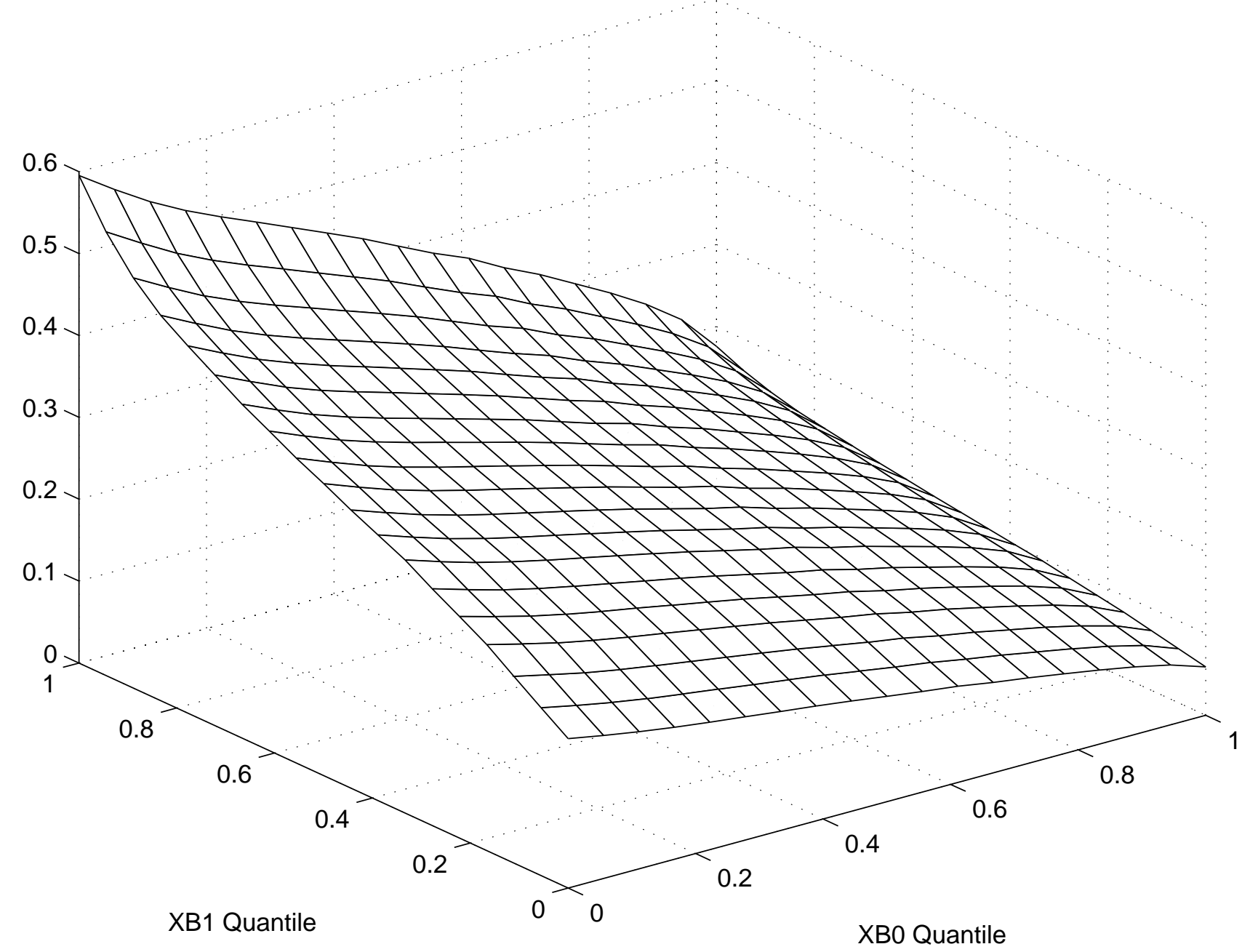


Figure 3: Prob(Delta=0|Xb1, Xb0)

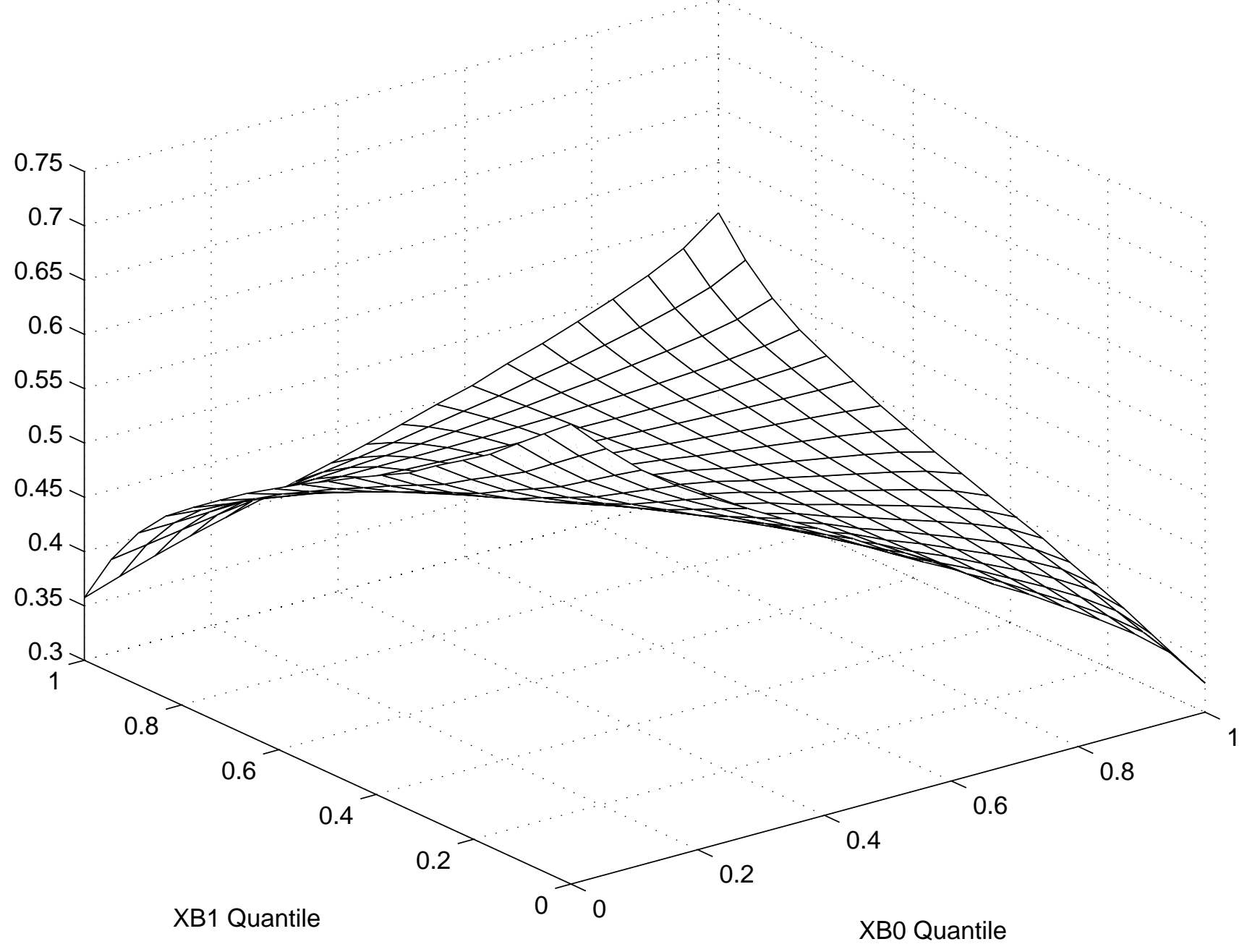


Figure 4: $\operatorname{Prob}($ Delta $=-1 \mid \mathrm{Xb} 1, \mathrm{Xb0})$

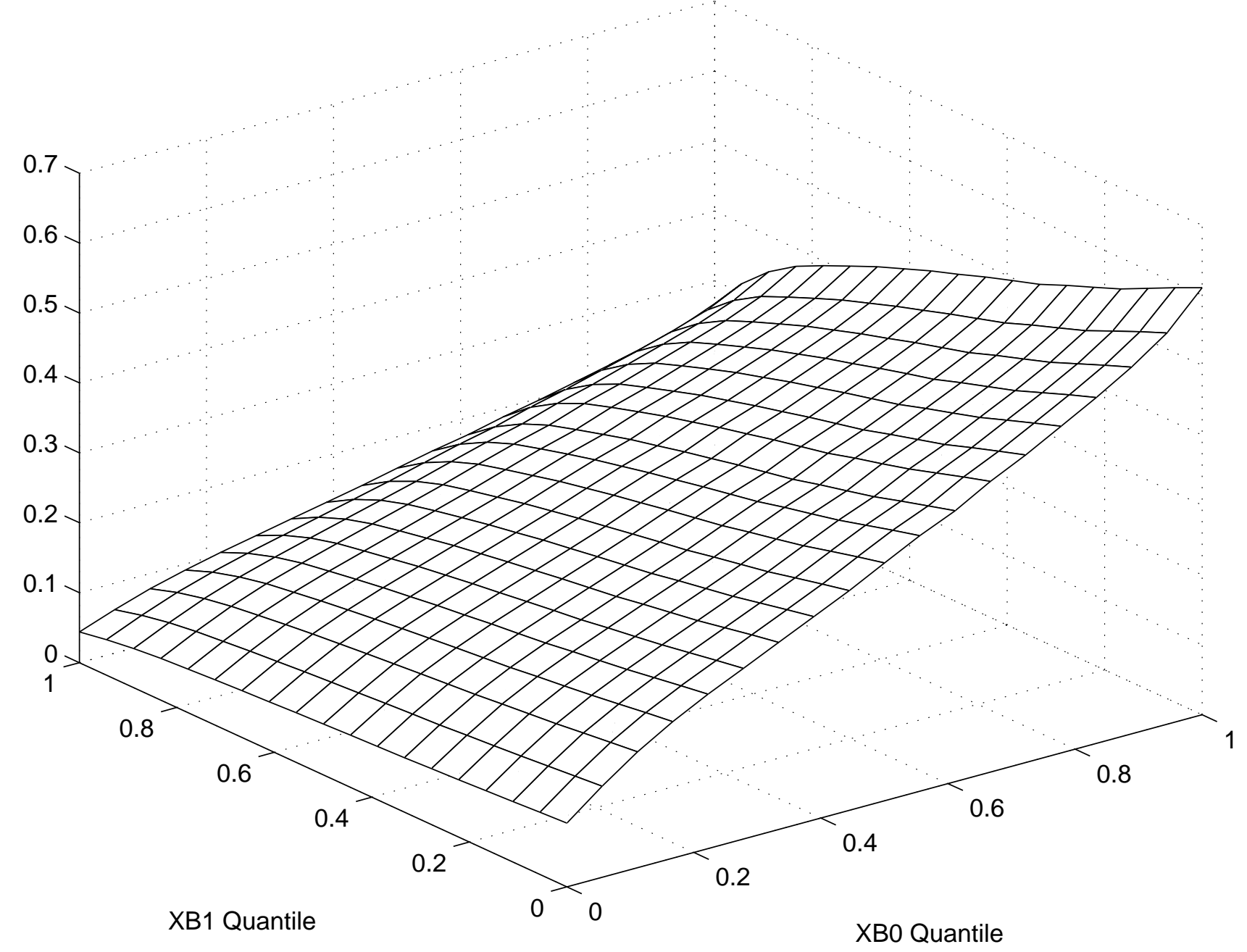




\section{Table 1: Means and Standard Deviations of \\ Characteristics for Participants and Nonparticipants.}

Number

Employment Rate, 1993

Income, $1988^{b}$

Income, 1992

One or More Children ${ }^{c}$

Child Older than $3^{d}$

Age

Actual Yrs of Work Experience

Education in Years

Degree of Rationing ${ }^{e}$

\begin{tabular}{cc} 
Participants $^{a}$ & Nonparticipants \\
\hline 1244 & 680
\end{tabular}

\begin{tabular}{cc} 
Mean & Mean \\
\hline 0.379 & 0.333 \\
$(0.485)$ & $(0.472)$ \\
61874 & 54707 \\
$(54420)$ & $(55324)$ \\
60509 & 52076
\end{tabular}

(68002)

(66599)

0.562

0.520

(0.496)

$(0.500)$

0.459

0.390

(0.499)

(0.490)

34.2

33.7

(10.1)

9.7

(10.7)

10.5

0.17

(0.12)
9.6

0.26

(0.16)

${ }^{a}$ Participants are those individuals who applied for a training program in 1989 and were registered in a training program for at least 5 days in the period from the beginning of 1989 until the end 1993. Nonparticipant are those individuals who applied for a training program in 1989 but never registered as a participant in a training program.

${ }^{b}$ Income measured in 100,000 Kroner(NOK). 1988 is the year before the application to VR training programs.

${ }^{c}$ This is a dummy variable for having one or more children.

$d$ This is a dummy variable for having a child over the age of three.

${ }^{e}$ Percentage of applicants in local districts who do not participate in VR training programs. 


\section{Table 2: Selection Equation}

\begin{tabular}{lrrr}
\hline \hline & Coeff. & t-value & Marg. $^{a}$ \\
\cline { 2 - 4 } Factor & 1.000 & & 0.2378 \\
Age & -0.018 & 2.34 & -0.0042 \\
Income $^{b}$ & 0.021 & 2.53 & 0.0049 \\
Education (years) One or More Children $^{c}$ & 0.050 & 2.53 & 0.0117 \\
Child Older than 3 $^{d}$ & -0.297 & 1.98 & -0.0706 \\
Actual Yrs of Work Exp. & 0.452 & 3.01 & 0.1075 \\
Degree of Rationing $^{e}$ & -0.379 & 0.93 & 0.0023 \\
\hline
\end{tabular}

${ }^{a}$ Marginal effects are defined as the analytical derivative averaged over the unconditional distribution of $Z: E_{Z}\left(\frac{\partial \operatorname{Pr}(D=1 \mid Z=z)}{\partial z_{k}}\right)$.

${ }^{b}$ Income measured in 100,000 Kroner(NOK). They are measured for 1988, the year before the application to VR training programs.

${ }^{c}$ This is a dummy variable for having one or more children.

${ }^{d}$ This is a dummy variable for having a child over the age of three.

${ }^{e}$ Percentage of applicants in local districts who do not participate in VR training programs. 


\section{Table 3: Employment Equations}

\begin{tabular}{lrrrrrr}
\hline \hline & \multicolumn{3}{c}{$\begin{array}{c}\text { Nonparticpation } \\
\text { Outcome }\end{array}$} & \multicolumn{3}{c}{$\begin{array}{c}\text { Participation } \\
\text { Outcome }\end{array}$} \\
\cline { 2 - 7 } & Coeff. & t-value & Marg. $^{a}$ & Coeff. & t-value & Marg. $^{b}$ \\
Factor & 0.433 & 1.28 & 0.1372 & -0.307 & 0.92 & -0.1072 \\
Age & -0.042 & 4.28 & -0.0042 & -0.005 & 0.90 & -0.0017 \\
Income $^{c}$ & 0.033 & 2.69 & 0.0103 & 0.000 & 2.45 & 0.0066 \\
Education (years) $_{\text {One or More Children }^{d}}$ & 0.094 & 2.95 & 0.0297 & 0.107 & 5.13 & 0.0372 \\
Child Older than 3 $^{e}$ & -0.769 & 3.35 & -0.2440 & 0.006 & 0.04 & 0.0019 \\
Actual Yrs of Work Exp. & 1.180 & 4.67 & 0.3744 & 0.108 & 0.72 & 0.0378 \\
\hline
\end{tabular}

${ }^{a}$ Marginal effects are defined as the analytical derivative averaged over the unconditional distribution of $X: E_{X}\left(\frac{\partial \operatorname{Pr}\left(Y_{0}=1 \mid X=x\right)}{\partial x_{k}}\right)$.

${ }^{b}$ Marginal effects are defined as the analytical derivative averaged over the unconditional distribution of $X: E_{X}\left(\frac{\partial \operatorname{Pr}\left(Y_{1}=1 \mid X=x\right)}{\partial x_{k}}\right)$.

${ }^{c}$ Income measured in 100,000 Kroner(NOK) and measured for 1988, the year before the application to VR training programs.

${ }^{d}$ This is a dummy variable for having one or more children.

${ }^{e}$ This is a dummy variable for having a child over the age of three. 


\section{Table 4: Marginal Effects of Regressors on Mean Treatment Parameters}

\begin{tabular}{lcc}
\hline \hline & $E_{X}\left[\frac{\partial E(\Delta \mid X=x)}{\partial x_{K}}\right]$ & $E_{X}\left[\frac{\partial E(\Delta \mid X=x, D=1)}{\partial x_{K}} \mid D=1\right]$ \\
& 0.0115 & 0.0123 \\
Age & -0.0037 & -0.0042 \\
Income $^{a}$ & 0.0075 & 0.0059 \\
Education (years) $_{\text {One or More Children }^{b}}$ & 0.2459 & 0.2602 \\
Child Older than 3 $^{c}$ & -0.3366 & -0.3582 \\
Actual Yrs of Work Exp. $^{d}$ & -0.0070 & -0.0083 \\
\hline
\end{tabular}

${ }^{a}$ Income measured in 100,000 Kroner(NOK) and measured for the year before the application to VR training programs.

${ }^{b}$ This is a dummy variable for having one or more children.

${ }^{c}$ This is a dummy variable for having a child

${ }^{d}$ Percentage of applicants in local districts who do not participate in VR training programs. 
Table 5: Mean and Distributional Treatment

Parameters

\section{ATE}

$E(\Delta)=-0.014$

(standard error $=0.08$ )

TT

$E(\Delta \mid D=1)=-0.110$

(standard error $=0.09)$

MTE with $\mathrm{U}_{\mathrm{D}}=\mathbf{2}$

$E\left(\Delta \mid U_{D}=2\right)=0.224$

(standard error $=0.17$ )

MTE with $\mathrm{U}_{\mathbf{D}}=\mathbf{0}$

$E\left(\Delta \mid U_{D}=0\right)=-0.014$

(standard error $=0.07$ )

MTE with $\mathrm{U}_{\mathrm{D}}=-\mathbf{2}$

$E\left(\Delta \mid U_{D}=-2\right)=-0.255$

(standard error $=.16$ )

\section{Distributional Version of ATE}

$$
\begin{gathered}
\operatorname{Pr}[\Delta=1]=0.225 \\
\operatorname{Pr}[\Delta=0]=0.532 \\
\operatorname{Pr}[\Delta=-1]=0.240
\end{gathered}
$$

\section{Distributional Version of TT}

$$
\begin{gathered}
\operatorname{Pr}[\Delta=1 \mid D=1]=0.178 \\
\operatorname{Pr}[\Delta=0 \mid D=1]=0.534 \\
\operatorname{Pr}[\Delta=-1 \mid D=1]=0.288
\end{gathered}
$$

Distributional Version of MTE with $\mathrm{U}_{\mathrm{D}}=\mathbf{2}$

$$
\begin{gathered}
\operatorname{Pr}\left[\Delta=1 \mid U_{D}=2\right]=0.350 \\
\operatorname{Pr}\left[\Delta=0 \mid U_{D}=2\right]=0.524 \\
\operatorname{Pr}\left[\Delta=-1 \mid U_{D}=2\right]=0.126
\end{gathered}
$$

Distributional Version of MTE with $\mathrm{U}_{\mathrm{D}}=\mathbf{0}$

$$
\begin{gathered}
\operatorname{Pr}\left[\Delta=1 \mid U_{D}=0\right]=0.219 \\
\operatorname{Pr}\left[\Delta=0 \mid U_{D}=0\right]=0.549 \\
\operatorname{Pr}\left[\Delta=-1 \mid U_{D}=0\right]=0.233
\end{gathered}
$$

Distributional Version of MTE with $\mathrm{U}_{\mathrm{D}}=\mathbf{- 2}$

$$
\begin{gathered}
\operatorname{Pr}\left[\Delta=1 \mid U_{D}=-2\right]=0.119 \\
\operatorname{Pr}\left[\Delta=0 \mid U_{D}=-2\right]=0.508 \\
\operatorname{Pr}\left[\Delta=-1 \mid U_{D}=-2\right]=0.373
\end{gathered}
$$




\section{Table 6: Effects of Norwegian VR Training on Employment (standard errors in parentheses)}

\begin{tabular}{|c|c|c|}
\hline \multirow[t]{2}{*}{ Unconditional Mean Differences $^{a}$} & \multicolumn{2}{|c|}{$\begin{array}{c}0.046 \\
(0.023)\end{array}$} \\
\hline & ATE & $\mathrm{TT}$ \\
\hline \multirow[t]{2}{*}{ Matching on Observables ${ }^{b}$} & 0.043 & 0.028 \\
\hline & $(0.023)$ & $(0.019)$ \\
\hline \multirow[t]{2}{*}{ Model without Unobs. Het. ${ }^{c}$} & 0.035 & 0.028 \\
\hline & $(0.023)$ & $(0.022)$ \\
\hline \multirow[t]{2}{*}{ Model with Norm. Distributed Unobs. Het. ${ }^{d}$} & -0.014 & -0.110 \\
\hline & $(0.080)$ & $(0.092)$ \\
\hline \multirow[t]{2}{*}{ Linear IV - Common Treatment Effect ${ }^{e}$} & -0.004 & -0.004 \\
\hline & $(0.078)$ & $(0.078)$ \\
\hline \multirow{2}{*}{$\begin{array}{l}\text { Linear IV - Treatment } \\
\quad \text { allowed to vary with } X\end{array}$} & 0.015 & 0.012 \\
\hline & $(0.043)$ & $(0.031)$ \\
\hline
\end{tabular}

${ }^{a}$ Unconditional mean difference is $\hat{E}\left(Y_{1} \mid D=1\right)-\hat{E}\left(Y_{0} \mid D=0\right)$.

${ }^{b}$ Matching estimates taken from Aakvik (1999b). These estimates are based on interval matching on the propensity score.

${ }^{c}$ Model without unobserved heterogeneity is based on latent variable model with $\alpha_{0}=\alpha_{1}=0$

${ }^{d}$ Model with normally-distributed unobserved heterogeneity is based on latent variable model with normal factor structure.

${ }^{e}$ Linear IV - common treatment effect is based on a LPM form for the outcome equation and a common treatment effect assumption, $(Y=X \beta+\gamma D+U)$ and linear IV estimation using $\operatorname{Pr}(D=1 \mid Z)$ as the instrument for D.

${ }^{f}$ Linear IV - treatment is based on a LPM form for the outcome equation while allowing the treatment effect to depend on observables, $\left(Y=X \beta_{0}+D\left(X \beta_{1}-X \beta_{0}\right)+U\right)$, with $\operatorname{Pr}(D=1 \mid Z) X$ used as the instrument for $D X$. 